Portland State University

PDXScholar

$1-1-1983$

\title{
A study of the modification of teachers' attitudes toward the hearing-impaired using two different types of treatment workshops
}

Anita Bell McClain

Portland State University

Follow this and additional works at: https://pdxscholar.library.pdx.edu/open_access_etds Let us know how access to this document benefits you.

\section{Recommended Citation}

McClain, Anita Bell, "A study of the modification of teachers' attitudes toward the hearing-impaired using two different types of treatment workshops" (1983). Dissertations and Theses. Paper 321.

https://doi.org/10.15760/etd.321

This Dissertation is brought to you for free and open access. It has been accepted for inclusion in Dissertations and Theses by an authorized administrator of PDXScholar. Please contact us if we can make this document more accessible: pdxscholar@pdx.edu. 


\title{
A STUDY OF THE MODIFICATION OF TEACHERS ' ATTITUDES TOWARD THE HEARING-IMPAIRED USING TWO DIFFERENT TYPES OF TREATMENT WORKSHOPS
}

\section{By}

Anita Bell McClain

A dissertation submitted in partial fulfillment of the requirements for the degree of

\author{
DOCTOR OF EDUCATION \\ in
}

PUBLIC SCHOOL ADMINISTRATION AND SUPERVISION

Portland State University

University of Oregon

1983 
TO THE OFFICE OF GRADUATE STUDIES AND RESEARCH:

The members of the Committee approve the

dissertation of Anita Bell MCClain presented May 4, 1983.

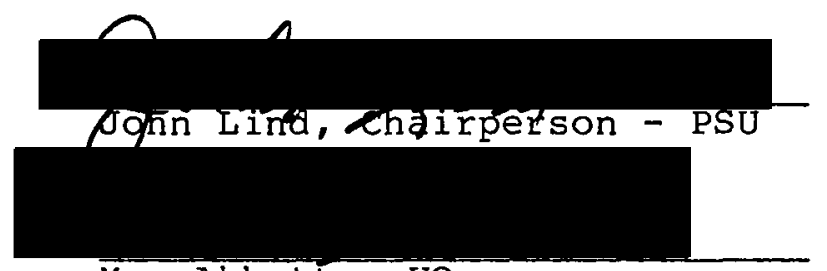

Max Abbott - UO

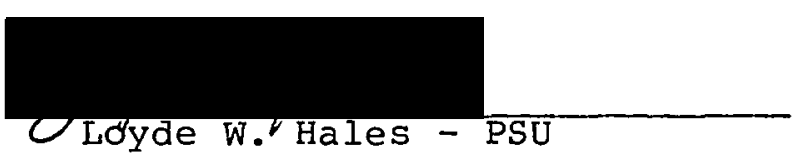

Lyde Wales - PSU

\section{Shelgon Máron - PSU}

APPROYED:

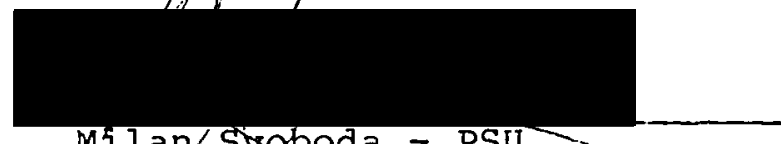

Milan/Swoboda - PSU -

William Brelje (Consultafft)

George V. Gúy, Bi-Universfty Program Coordinator (Portland Stafl Universitv)

Max Abbott, Bi-University Program Coordinator (University of Oregon )

Donald J. Leu, Deah, of the School of Education (Portland State University)

Stanley Rauch, Dean of Graduate Studies and Research (Portland State University) 
AN ABSTRACT OF THE DISSERTATION OF Anita McClain for the Doctor of Education in Public School Administration and Supervision presented May 4, 1983

Title: A Study of the Modification of Teachers' Attitudes Toward the Hearing-Impaired Using Two Different Types of Treatment Workshops.

APPROVED BY MEMBERS OF THE DISSERTATION COMMITTEE:

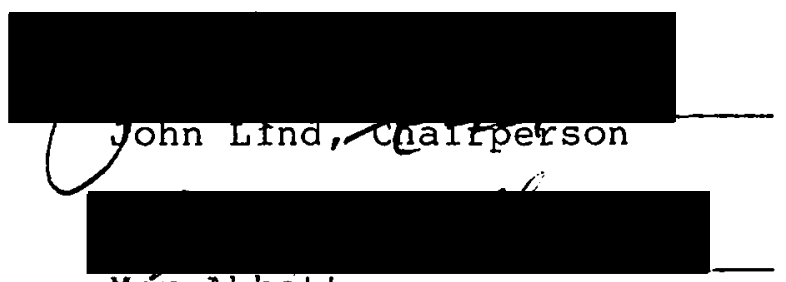

Máx Abbott

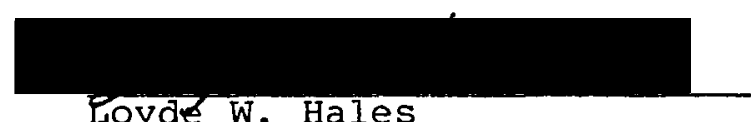

Loyde $W$. Hales

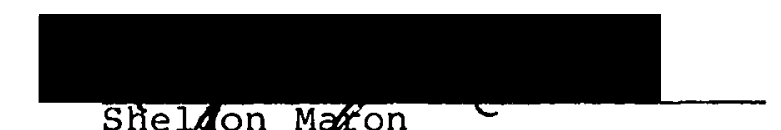

Shelfign Magron

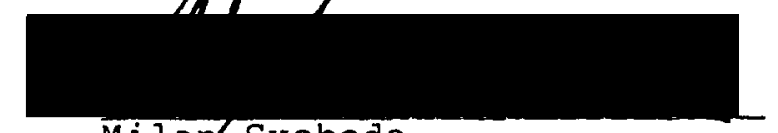

Milap Svoboda

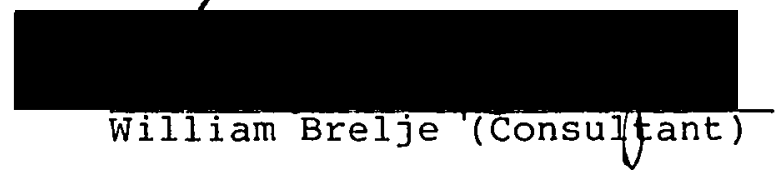

This experimental study grew out of the ideas gleaned from a review of literature which indicated that the attitudinal role of the classroom teacher serves as a model 
for students. A justification of the need to modify behaviors toward the hearing-impaired became apparent. The significance of effective workshop procedures could result in notable implications for school district planning and implementation of an in-service education plan. An experimental study was conducted to determine if teacher attitudes toward the hearing-impaired can be modified using two types of in-service workshops, passive versus active participation.

Three groups of randomly selected regular classroom teachers at the elementary level from a West coast suburban school district were used for this investigation $(\underline{N}=86)$. One group served as a control, a second group participated in active involvement workshops regarding the hearing-impaired student, and the third group attended passive involvement workshops regarding the hearingimpaired student. Immediately following the workshops, participants were administered two scales designed to measure attitudes toward the hearing-impaired.

The research hypothesis for the study was that not all subpopulation means of the scores of teachers for both scales will be equal. ( $\mathrm{H}_{1}$ : not all 's are equal.) The statistical hypothesis stated that all subpopulation means of the scores of teachers for both scales will be equal. $\left(\mathrm{H}_{\mathrm{O}}: \mu\right.$ active $=\mu$ passive $=\mu$ control. $)$ 
The results, after submitting the data to SPSS Subprogram, ONEWAY (Nie et al., 1975), with alpha set at .05 yielded no statistically significant differences among the groups. The statistical hypothesis was not rejected. The results of this study imply the need for school districts to pre-test teachers' attitudes in determining a need for specific in-service courses. School districts should consider requiring in-service courses for teachers whose pre-test scores indicate negative attitudes. Another implication to consider for effective in-service education is the duration of the workshop. The workshops designed for this study were one hour in length and did not result in effective modification of attitudes toward the hearing-impaired. This investigation suggests that research is neede' i.o establish the relationship between effective in-service training and positive attitude development. 
To Don and Allison whose

support and understanding

were unending 


\section{ACKNOWLEDGEMENTS}

The writer is indebted to several individuals and groups. Many thanks go to Beaverton School District, Beaverton, Oregon, which allowed the investigator to conduct research in that district. Lewis and clark College faculty and staff of the Education Department and Special Education Programs--Hearing-Impaired were very supportive and helpful.

Grateful thanks go to the individuals who served on my Doctoral Advisory Committee and whose suggestions were very helpful. Particularly valuable was the support of Dr. John Lind, Chairperson of the committee, and Dr. Loyde Hales, who helped with the design of the statistics for this investigation.

Special thanks to my husband, Don, and daughter, Allison, whose encouragement was priceless. Finally, thanks to Barbara Wiegele, whose competence as a word processor was most helpful. 
DEDICATION . . . . . . . . . . . . . . . i i

ACKNOWLEDGEMENTS . . . . . . . . . . . . iv iv

LIST OF TABLES . . . . . . . . . . . . viii

LIST OF FIGURES. . . . . . . . . . . . . . $\mathrm{x}$

CHAPTER

I. INTRODUCTION ............ 1

Introduction ............ 1

Statement of the Problem . . . . . . 4

Purpose of the Study .......... 4

Definition of Terms. . . . . . . . . 4

Description of the Research. ..... 5

Significance of the Study. . . . . . 5

II. REVIEW OF THE LITERATURE . . . . . . . 7

Introduction . . . . . . . . . 7

Attitudes Toward Behaviors of the

Handicapped. . . . . . . . 8

Attempts to Modify Teachers' Attitudes Toward the Handicapped ...... 13

Status of the Hearing-Impaired Among the Handicapped. . . . . . . 17

Attitudes Toward Behaviors of the

Hearing-Impaired ....... . 19

Attempts to Modify Attitudes Toward the Hearing-Impaired . . . . . . 22

The Need for In-Service Education Regarding Perceptions of the HearingImpaired . . . . . . . . . . 24

Effective In-service Workshops Sessions. 28

Adult Learning Theories and Styles Related to In-Service Education. . . 33

Planning and Organization of In-Service Education. . . . . . . . . . 41

Effective In-Service Workshops Relevant to the Handicapped ....... 56

Effective In-Service Workshops Relevant to the Hearing-Impaired. . . . . . 58

Summary. . . . . . . . . . 61 
III. NETHODS AND PROCEDURES . . . . . . . 63

Introduction .. . . . . . . . 63

Research Design. . . . . . . . . . 64

Instrument Selection . . . . . . . 65

Sampling and Sampling Procedures. . . 69

Data Collection. . . . . . . . . 77

Design and Implementation of Active

Involvement Workshops. . . . . . . 79

Design and Implementation of Positive

Involvement Workshops. . . . . . 85

Statistical Design . . . . . . . . 87

Hypotheses . . . . . . . . . . 88

IV. PRESENTATION OF DATA . . . . . . . . 90

Introduction . • • . • . • . . • . 90

Reliability and Intercorrelations of

the Tests................ 91

Descriptive statistics for the Tests: 92

Attitudes to Deafness Scale. . . . . 97

Teacher Scale of Attitudes Toward

the Hearing-Impaired Student . : . . 98

V. CONCLUSIONS AND IMPLICATIONS . . . . . 100

Introduction .. . . . . . . 100

Conclusions. . . . . . . . . . . 100

Implications ............. 103

REFERENCE NOTES. • . • . . . . . . . . . 107

BIBLIOGRAPHY . . . . . . . . . . . . . 108

SELECTED BIBLIOGRAPHY. . . . . . . . . . . . 120

APPENDICES • . . . . . . . . . . . . . . . 123

Appendix A . . . . . . . . . . . . 123

Appendix B ................. 129

Appendix C . . . . . . . . . . . . . 131

Appendix D . . . . . . . . . . . . . . . . 133

Appendix E . . . . . . . . . . . . . . 135

Appendix F . . . . . . . . . . . . 137

Appendix G . . . . . . . . . . . . . . . 139 
Appendices (continued) PAGE

Appendix H . . . . . . . . . . . . . . 141

Appendix I . . . . . . . . . . . . . . . . 144

Appendix J . . . . . . . . . . . . . . 147

Appendix K . . . . . . . . . . . . . 150

Appendix L . . . . . . . . . . . . . . 152

Appendix M . . . . . . . . . . . . . 155

Appendix N . . . . . . . . . . . . . . . 158

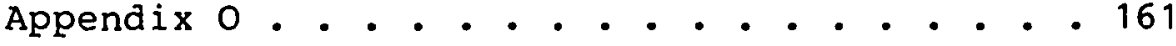




\section{LIST OF TABLES}

I Motivations for ISTE Participation . . . 31

II Questions Teachers Ask as They Move Through the Stages of Concern. . . . 34

II Experience Impact of Activities. . . . . 46

IV Coefficients of Correlation and Coefficients Alpha for the Teacher Scale of Attitudes Toward the Hearing-Impaired. . . . . 68

$\mathrm{V}$ Selection of Participants. . . . . . 71

VI Initial Responses of Sampling. . . . . . 72

VII Second Response of Initial Sampling. . . 74

VIII Requests from Reserve Pool. . . . . . . 75

IX Total Participants in Study . . . . . . 76

$\mathrm{X}$ Time Schedule of Active Involvement Workshop. . . . . . . . . . . . 79

XI Active Involvement. . . . . . . . . 80

XII Time Schedule of Passive Involvement Workshop. . . . . . . . . . . 85

XIII Passive Involvement Groups. . . . . . 85

XIV Coefficients of Reliability and InterCorrelation for Each Test by Individual Groups and Total Sample... . . . . 92

XV Attitudes to Deafness Scale Frequency Distribution of Attitude Scores by Group and Total Scores. . . . . . . 94

XVI Teacher Scale of Attitudes Toward the Hearing-Impaired Student Frequency Distribution of Attitude Scores by Group and Total Scores. . . . . . . . . . 
XVII Summary statistics for the Attitudes to Deafness Scale. . . . . . . . . . 96

XVIII Summary Statistics for the Teacher Scale of Attitudes Toward the Hearing-Impaired Student

XIX Analysis of Variance Summary of Statistics for the Attitudes to Deafness Scale . .

$\mathrm{XX}$ Analysis of Variance summary of statistics for the Teacher Scale of Attitudes Toward the Hearing-Impaired Student. . . . . . 


\section{LIST OF FIGURES}

Figure

Page

1 Adult Learning Theory and Its Implication for Training . . . . . . . . . . 35

2 Formula for Group Interaction. . . . . 53

3 Selected Activities Arranged by Purpose, Experience Impact Required, and

Group Size . . . . . . . . . . 55 
CHAPTER I

\section{INTRODUCTION TO THE STUDY}

\section{Introduction}

Integrating the hearing-impaired child into the regular classroom introduces a new dimension to the organization and teaching patterns of the classroom teacher.

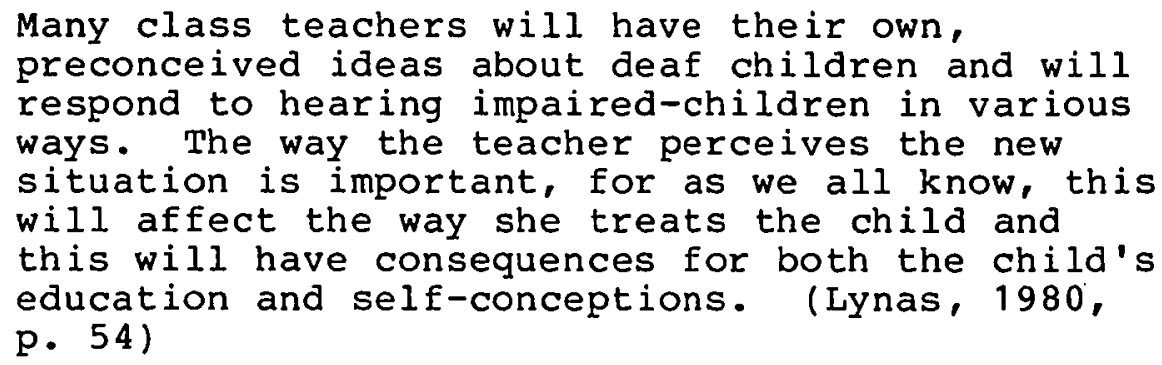

The attitudes of regular classroom teachers toward the hearing-impaired child are of major concern for successful integration of that student into the regular classroom. "The effectiveness of mainstreaming may be related to the attitudes of the receiving teachers" (Williams \& Algozzine, 1979, p. 1). Anderson (1968) seems to agree with Williams and Algozzine that schools need to maintain a healthy atmosphere. A healthy environment creates a stable emotional atmosphere. The most influential person in the classrcom is the teacher. 
Yater (1977) stated that "the classroom teacher is the pivotal professional affecting the hearing-impaired child's public shool learning situation" (p. 49). The more positive the teacher is toward the hearing-impaired child, the more likely the student will be successful.

An obvious educational argument for integrating the hearing-impaired child into the regular classroom is that the environment is more stimulating. The regular classroom environment and curriculum tend to be more stimulating and more academic than that available in a special-education setting. In the mainstreamed environment the hearing-impaired child can learn from a greater variety of peers and adults who maintain generally higher academic standards.

From a social point of view, the regular classroom setting provides an opportunity for the hearing-impaired child to adjust to socializing and living within the normal hearing community. Thus, the impaired child can find ways to cope in a hearing-speaking environment. Further, this handicapped child can live at home rather than attend a boarding school. Academically and socially, the hearing-impaired child is more likely to attain a more normal language development when surrounded by everyday speech. This use of natural language can allow the child to gain confidence living in the hearing-speaking community. Lastly, the integration concept offers hearing 
children an opportunity to understand and accept human differences (Lynas, 1980).

Lapp (1957) conducted a study in which the results reinforce the importance of the role of the classroom teacher. Whether the teacher accepts or rejects a handicapped child, that decision initiates the attitudinal direction the reguiar students will assume. In other words, if a teacher displays an accenting attitude toward a handicapped child, it is likely that the students in that classroom will respond positively toward the child. Haring (1957) suggested that since teacher attitudes make a difference in establishing a positive adjustment of the handicapped child, it seems significant to determine what factors lie behind the development of positive attitudes toward such children. Mandell and Strain (1978) supported the use of workshops when they found that in-service experiences regarding special-education topics tend to elicit positive attitudes toward mainstreaming. For a more effective workshop, Harris and Bessent (1969) advocate teacher involvement during in-service sessions rather than passive listening. Studies of teacher behavior (Good \& Brophy, 1973; Ryan \& Moffit, 1974; and Bourdeau \& Ryan, 1978) result in notable implications for in-service training of teachers such as the relationship of teachers' attitudes and the manner in which teachers interact with students. 
Statement of the Problem

With the implementation of PL 94-142, more hearing-impaired children are being mainstreamed into regular classrooms. Many teachers feel unprepared to deal with these children and as a result may have established negative attitudes toward such children.

\section{Purpose of the Study}

It was the intention of this investigator to determine if teacher attitudes toward the hearing-impaired can be positively modified by using two contrasting types of workshops, passive versus active participation. The study then attempted to determine which type of workshop, active or passive, results in the most significant changes in teachers' attitudes.

\section{Definition of Terms}

Hearing-impaired--continuum of hearing loss, mild-moderate-severe-profound.

Regular classroom teacher--teacher whose students are "normal" as opposed to handicapped.

Regular classroom--classroom of "normal" children as opposed to special education.

In-service workshop--further education and professionalism of teachers through learning opportunities to improve performance. 
Active participation--actively engaging in pursuing an objective; for example, role-playing or simulation to "feel" a handicap.

Passive participation--idle participation, uninvolved; lecture without interaction.

Attitude--positive or negative emotion for or against a person or idea.

Simulation--setting up a structure which utilizes reality, but not the true situation.

Experiential--working with the real situation; student-teaching as an example.

\section{Description of the Research}

The research problem was addressed by randomly selecting three groups of regular classroom teachers from a West coast suburban school district. The investigator collected data after presenting active participation and passive participation in-service workshops regarding the understanding of hearing-impaired children.

\section{Significance of the study}

There is a need for well organized in-service workshops for regular classroom teachers receiving hearing-impaired children. This investigation reflects Haring's idea (1957) that orientation programs are an effective approach to improving classroom integration for exceptional children. Owen (1978) wrote, "Regular 
classroom teachers need adequate university preparation or in-service training in the most appropriate techniques for working effectively with a handicapped child" (p. 59).

It has been estimated that several million children in regular classrooms have mild to severe hearing losses. In-service workshops must be developed specifically to meet the needs of hearing-impaired children (Davis et al., 1981). In agreement with Martin (1974), this investigator recognizes the need to provide in-service training for regular classroom teachers in order to keep pace with the mainstreaming efforts. In further agreement with Rusalem (1967), the investigator perceives the significance of modifying attitudes in a positive direction for successfully integrating exceptional children into the regular classroom. Findings from a pertinent study by Haring, Stern, and Cruickshank (1958) "strongly suggest that integration can be more effectively achieved when accompanied by the supportive experience which can be provided by a workshop" (p. 132). Regarding the re-education of regular classroom teachers who receive handicapped children, Harasymiw and Horne (1975) stated the following: "Retraining programs, in-service experiences and workshop approaches would appear to be viable alternatives" (p. 157). 
CHAPTER II

REVIEW OF THE LITERATURE

\section{Introduction}

Implementation of PL94-142, which mandated that all handicapped children be educated in the least restrictive environment, has aroused many concerns regarding professional competencies. Are regular classroom teachers prepared to teach exceptional children--specifically the hearing-impaired?

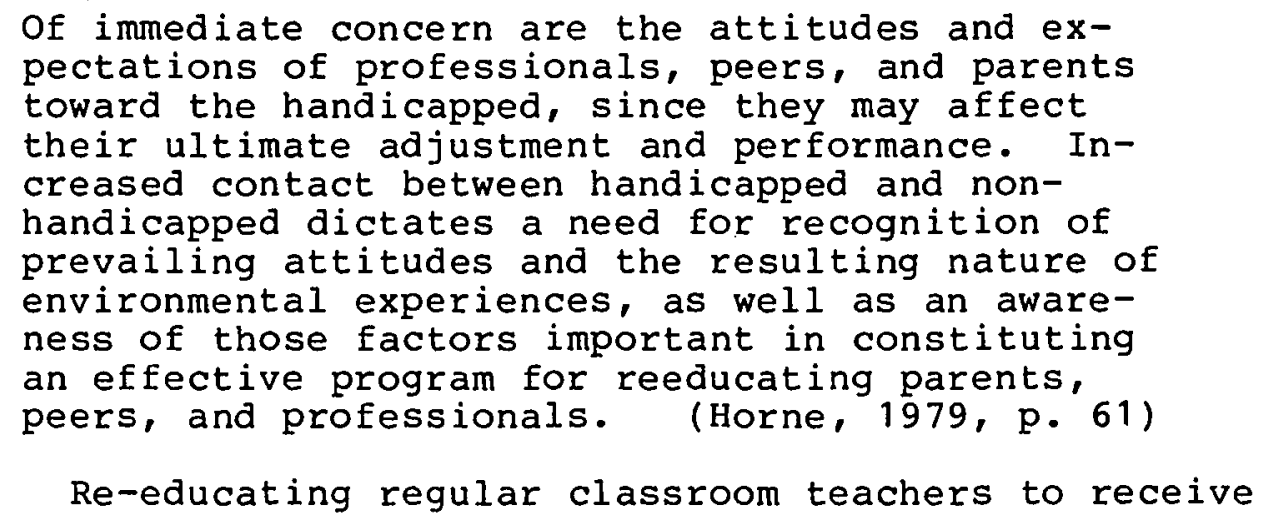


teachers receiving the hearing-impaired child can be instrumental in the positive modification of attitudes toward such children.

\section{Attitudes Toward Behaviors of the Handicapped}

A number of investigations suggest a relationship exists between teacher attitudes and the behavior of the handicapped child. Silberman (1969) in an interview process requested that third-grade teachers identify one student per attitude group who best fits the categories of "attachment," "concern," "indifference," and "rejection." The "attachment" child was that whom the teacher would select to have in his/her classroom for another year because the child was so enjoyable. The "concern" child was that who the teacher felt needed undivided attention. The child selected for the "indifference" category was the one whom the teacher was least prepared to discuss if a parent dropped in unexpectedly. Lastly, the "rejection" labeled child was the student the teacher would prefer be removed from his/her classroom. Silberman then observed the behavior of the Eeachers toward these groups of students. The study disclosed that teacher attitudes were reflected in their behavior toward students. Second, attitudes of "rejection" were clearly expressed. Lastly, students were cognizant of the expressed attitudes of their teacher. Moreover, these apparent teacher attitudes might contribute to the development of specific peer attitudes. 
Subsequently, Good and Brophy (1972) replicated the work of Silberman (1969). These investigators extended the research in that they sampled teachers from a different grade level and selected schools which represented three socio-economic levels, upper-middle-class white, lower-class white, and lower-class black. "The data support Silberman's conclusion that teachers' attitudes toward children do correlate with differential teacher behavior; however, the present data also suggest that all four teacher attitudes lead to differential teacher behavior" (p. 622).

These data show, as Jackson and Lahaderne (1967) have previously reported, that classroom life is an uneven affair, with some students receiving much more teacher contact than others. Teachers' attitudes toward students will affect the quality and quantity of contacts they have with students. (Good \& Brophy, 1972, p. 623)

Bourdeau and Ryan (1978) replicated and extended the works of Silberman (1969) and Good and Brophy (1972) into the preschool. The unique preschool setting in which a child interacts with several teachers permits the investigator to examine several teachers who might have differing attitudes regarding the same child. "It was shown that more instructional contacts were made with the attachment students than with those in any other attitude group. Also, an attitude of concern led to more instructional contacts than did the attitudes of indifference or rejection" (p. 283) 
Wandt (1952) surveyed 240 teachers, requesting that they reveal their attitudes toward administrators, supervisors, pupils, parents, teachers, non-teaching employees and classroom and administrative procedures. An attitude scale, "Inventory of Teacher Opinion," was constructed. The median Spearman-Brown reliability of the scale was .81 . Several of the results of this study indicated that teachers' attitudes toward groups are measurable and that there exists a relationship between attitudes and behaviors. Wandt (1952) concluded that teachers' attitudes might become an integral assessment criterion for measuring the personality of the classroom teacher.

Other investigators of teacher behavioral attitudes have researched specific handicap conditions. DeLeo (1976) researched the area of attitudes of various educators toward mainstreaming the Educable Mentally Retarded (EMR) student. The study concluded that the regular classroom teachers displayed the least favorable attitudes toward EMR children. Recently, Vacc and Kirst (1977) conducted a study of 149 regular classroom teachers and their attitudes toward emotionally disturbed children. They indicated that the behaviors and attitudes of teachers relate to the learning atmosphere in which emotionally disturbed children must operate. Thus, they felt it important to collect data regarding teacher attitudes on 
mainstreaming. Questionnaire responses indicated that, although regular classroom teachers felt it might be beneficial for emotionally disturbed children to remain in regular classrooms, they believed they should be segregated in special classrooms. They felt that emotionally disturbed children would not be accepted by normal children and that their presence in the regular classroom would be pernicious to non-handicapped children. They further felt that emotionally disturbed children would negatively affect teachers. The regular classroom teachers--918 of those responding--also believed that they should have at least one course in special education to better acquaint themselves with exceptional children and their needs.

Panda and Bartel (1972) found that teachers ranked all handicapping conditions of children significantly below the children considered to be normal or gifted. Contrary to their expectations, teachers with special education course work and experience did not respond any more favorably toward the handicapped child than did teachers with no such background. Jaffe (1966) had reported earlier that experience in working with exceptional children leads toward more positive attitudinal behaviors. To summarize data available regarding attitudes of teachers toward the handicapped from a behavioral 
perspective, Conine (1969) suggested that "favorable attitudes must be fostered among teachers who influence the value system of our future generations" (p. 280). In study in which 1000 teachers were randomly selected in a large city in the Mid-West, 501 responded and of that response 473 were self-described non-handicapped teachers which the study was based. Conine (1969) used the ATDP-O scale, Attitudes Toward Disabled Persons Scale, Form 0. This Likert-type scale has been administered to more than 1200 persons and "evidence has been presented that it is both reliable and valid for use with either disabled or non-disabled persons" (Yuker, Block and Campbe11, 1960, p. 13). This scale enables administrators to more appropriately place those handicapped students who are to be mainstreamed.

The placement of handicapped youth in less restrictive environments or environments which are closer to the realities of the world where these youngsters must reside is a laudable and nondebateable goal. The major issue, however, relates to the readiness of the pupil to be "mainstreamed" and the readiness of the "mainstream" which is to accept the pupil. If either of these is not prepared, the needs of the weaker will not be met. The weaker of the two most typically is the child. (Pappanikou, 1979, p. 51)

Brophy and Good (1974) suggest that if teachers have the appropriate attitudes, they will exhibit behavior whic is supportive, patient, and confident. Such behaviors should result in an expectation that students can enjoy learning. Positive expectations are requisite. "To the 
extent that they initiate behavior that leads to selffulfilling prophecy effects, they help prevent and solve problems that would otherwise appear" (p. 350).

The studies reviewed to this point suggest that regular classroom teachers reflect negative acceptance of special children into their classrooms. Teachers' attitudes affect student behavior and progress (Rosenthel and Jacobson, 1968). The "Rosenthal Effect" or "Pygmalion Effect" has been acknowledged widely and has had heuristic influences valuable to the study of the effects of teachers' attitudes(Alexander \& Strain, 1978).

\section{Attempts to Modify Teachers' Attitudes}

\section{Toward the Handicapped}

Hudson, Graham, and Warner (1979) suggested that the education of handicapped students is no longer exclusive to special educators. Regular educators must accept responsibility for teaching exceptional children if mainstreaming is to be successful. Critical to the principle of mainstreaming are appropriate attitudes of receiving teachers. However, when 151 regular elementary teachers responded to an attitude questionnaire, they discovered that the majority did not support mainstreaming. These results indicate a need for nodifying teacher attitudes for implementation of effective mainstreaming. Public Law 94-142 not only mandates appropriate education programs 
for the handicapped, but it also mandates in-service training for special and regular education teachers.

Kraft (1973) and Payne and Murray (1974) suggested that teacher effectiveness can become more positive through in-service programs. Payne and Murray (1974) found that principals ranked in-service training as the priority need of regular classroom teachers who are asked to integrate handicapped children. "Teaching, like anything else, can be studied, and teachers who are willing to study their own behavior and who seek feedback from others will gain valuable insights and new alternatives for increasing their repertoire of classroom skills" (Brophy \& Good, 1974, p. 352). Concurring with the above, Graham, Hudson, Burdg, and Carpenter (1980) concluded in their study that regular classroom teachers must receive training which will enable them to improve mainstreaming techniques necessary to receive and appropriately educate handicapped students. In an earlier article by three of these authors it was suggested that

An effective mainstreaming program is based, to a great extent, on the cooperation and good will of both special and regular educators. If the regular classroom teacher views mainstreaming unfavorably, the success of the program is in jeopardy. To alter regular classroom teachers' attitudes, it will be necessary to provide them witt inservice and preservice training to strengthen their level of skill competency and to modify their attitudes. (Hudson, Graham, \& Warner, 1979, p. 62)

Mandel and Strain (1978) studied eight variables found to be significant predictors of positive attitudes toward 
mainstreaming. One of these variables, in-service education, confirmed findings by Glass and Meckler (1972) that such training produces more positive attitudes toward handicapped children.

Glass and Meckler (1972) conducted a summer workshop for teachers who would be receiving handicapped children into their regular classrooms in the fall. Using the preand post workshop administration of the Minnesota Teacher Attitude Inventory (MTAI) and a self-report inventory developed by the investigators, effects of the workshop were evaluated. Trainees viewed themselves as more positive toward the notion of mainstreaming and more able to teach handicapped children.

In an extensive study by Haring, Stern, and Cruickshank (1958), the investigators sought to determine the knowledge teachers initially possessed regarding handicapped children, their attitudes toward such children, their own personality traits, their feelings toward themselves, others, and exceptional children. The teachers were reassessed after a workshop presentation to determine if changes had occurred. Teachers and administrators were provided 15 workshops over a period of 30 weeks. Eight areas of exceptionality were included in the workshops. During two-hour sessions the participants received a lecture on exceptionality the first hour and were asked to participate in discussion relevant to the presented topic the second 
hour. Pre- and post-testing were conducted during the first and last sessions of the workshops. The findings suggested that integration can be effectively attained when supportive experience is provided in a workshop. The teachers as a total group became more positive in their responses to pictures of handicapped children.

The meaning of this study stands out clearly with regard to programs involving increased acceptance for exoentianal children. There seems to be little doubt but that a program of this nature offers a supportive experience for teachers who are engaged in teaching exceptional children within their classrocm. The ideas, assistance, and support which they gain from a workshop at the time this is needed are more apt to bring about significant changes in their attitudes and understanding. (Haring, Stern \& Cruickshank, p. 133)

Williams and Algozzine (1977) selected 363 teachers to participate in a study designed to determine teacher attitudes toward mainstreaming the physically handicapped, socially/emotionally disturbed, educable mentally retarded, and learning disabled children. Seventy-four percent of the teachers returned questionnaires $(\mathrm{N}=267)$. Ninety percent of the teachers were certified in regular education, 328 had Master's degrees and less than $30 \%$ were teaching or had taught handicapped students. It was concluded that teachers felt that physically handicapped and learning disabled students should receive more services than disturbed or retarded children. Thus, a hierarchy of acceptability was established. "Attitude change can neither be legislated nor forced. The process involved in 
reeducation is similar to that used in the teatment of some phobias--desensitization" (Pappinkou, 1979, p. 52).

Besides modification of professionals in attitude studies, investigations have resulted in positive attitude change in students through re-education (Rusalem, 1967; Rapier, Adelson, Carey, \& Croke, 1972; Cantrell \& Cantre1l, 1976; and Lazar, Gensley, \& Orpet, 1971).

It would appear from the research that attitudes can be positively modified and that well organized in-service programs help to facilitate such acceptance. Provision of support services, experience, central leaders such as the principal, and specially broadcasted media programs (Mitchell, 1976) will also create positive attitudes.

\section{Status of the Hearing-Impaired Among the Handicapped}

Investigations regarding the labeling of exceptional students affect teacher perceptions of specific types of handicaps. "Precisely which students teachers prefer more or less among the handicapped is questionable" (Horne, 1979, p. 62). However, Shotel, Iano, and McGettigan (1972) found that teachers reacted more positively toward the learning disabled than to emotionally disturbed children. Teachers showed the least preference toward the educable retarded. Combs and Harper (1967) concluded from an investigation of the effects of labels on teachers' attitudes toward handicapped children that labels do indeed cause a difference in 
acceptability. Further, Gillung and Rucker (1977) found that due to the negative connotations of labels, teachers lower their expectations of the child. Harasymiw and Horne (1976) investigated teacher attitudes toward specific handicaps. They collected data from 352 urban teachers using a Likert and a social distance type questionnaire designed to elicit attitudes. Given ten handicapping conditions teachers rated deaf as seventh in order of preference.

Kvareceus (1956) measured the degree of acceptability of handicapped children maintained by 84 professional workers, mainly regular classroom teachers. Using a rank order correlation (rho) it was found that the teachers ranked deaf and hard-of-hearing last in the category, "most prefer to teach." The category, "know most about," deaf and hard-ofhearing, was again ranked last.

Tringo (1970) surveyed 455 subjects regarding their attitudes toward specific groups of disabilities by asking the subjects to rate their preferences toward 22 handicapping conditions. High school students ranked deafness as ninth. College undergraduates, graduates, and professionals ranked deafness as seventh. The order of preference in the studies by Tringo (1970), Shears and Jensema (1969) and Harasymiw, Horne, and Lewis (1976) seem to follow results of previous studies. Specifically, the normal population tends to rank physically disabled first, followed by sensory disabled and the brain-injured last. 
It becomes apparent that a hierarchy of preferences toward the handicapped does exist. The hearing-impaired tend to be in the middle of this range. One could investigate what has been done specifically to survey attitudes toward the hearing-impaired and to modify attitudes for a more positive acceptance of the hearing-impaired.

\section{Attitudes Toward Behaviors of the Hearing-Impaired}

Cowen, Bobgrove, Rockway, and Stevenson (1967) developed a scale which specifically measures attitudes toward the hearing-impaired. Until the 1960 's, attitude scales were designed to measure handicaps in general. The Attitudes to Deafness Scale (Cowen et al., 1967) was a replicated instrument based on a scale for blindness which had been developed in 1963 by Cowen and Cowen, originally constructed by Cowen, Underberg, and Verrillo (1958). Similarly, attitude measures were beginning to be developed relevant to other specific handicaps such as blindness and orthopedic conditions (Lowenfeld, 1963; and Cruickshank, 1963).

Cowen, Bobgrove, Rockway, and Stevenson (1967)

presented the reliability base for the Attitude to Deafness Scale. In final analysis of the field-test base, a corrected split-half reliability of .83 was reached for the final scale of 25 items. For the total sample, the mean score was 51.02 with a standard deviation of 7.32 . This 
scale has been used by others (Blake, 1970, 1971; and Bobgrove, 1965). Siller, Ferguson, Chipman, and Vann (1967) developd a Disability Factor Scale. Ferguson (1970) used a deafness form of this test with 674 hearing subjects. A third test developed specifically to measure attitudes toward hearing-impairments was developed by Poulos (1971). He adapted the Attitude-Behaviors Scale by Jordan, Morin, Maule, and Dell Orto (1970).

What do hearing persons feel toward a hearing-impaired person and toward the impairment itself? Horowitz and Rees (1962) studied 266 subjects and found much confusion existed regarding hearing-impairments and the hearing-impaired. Definitions of deaf and deafness were confusing. Subjects tended to believe that the hearing aid cured all hearing problems. Subjects felt that deaf persons, especially those who wore hearing aids, should learn to speak as well as hearing persons. Lastly, subjects indicated an awareness that deaf people are friendly with hearing persons. "Although friendly attitudes were often verbalized, there was a tendency in all groups to be somewhat patronizing, as shown by the frequent explanations of the ways in which deaf people benefit from associating with the hearing" ( $p$. 187). Schroedel and Schiff (1972) used the Attitude to Deafness Scale and the Disability Factor Scales to determine attitudes of hearing-impaired persons and of normal hearing persons. Both scales indicated that the hearing-impaired 
subjects had more negative attitudes toward the hearingimpaired than did the hearing subjects. Also, hearingimpaired subjects perceived hearing persons to have more negative attitudes than what were actually occurring among the normal population. "However, the possibility exists that attitude scores of deaf persons reflect actual experiences, while hearing persons have not thought much about their feelings towards deafness, and give spuriously positive scores" (p. 69).

Murphy, Dickstein and Dripps (1960) conducted a study to determine educators' attitudes toward the hearing handicapped. The study was prompted by their beliefs that children who are loved and accepted are more likely to be successful socially and educationally. Teachers attitudes and feelings toward the hearing-impaired child "may be critical in terms of immediate or eventful effects upon the child's adjustment" (p. 208). In their study, 309 educators (or education majors) were asked to rank eight categories of handicapped persons whom they would least prefer to teach and most prefer to teach. They found that "hearing handicapped children are ranked by the total group in the second-or third-last place, being exceeded only by the delinquent and visually handicapped groups" (p. 209). Murphy, Dickstein and Dripps (1960) developed the following series of implications based on their observations. 
1. A teacher is more comfortable and develops a more positive attitude toward a child the more knowledge the teacher has about the handicap itself.

2. There is a need for properly trained persons to work with the hearing-impaired.

3. The hearing-impaired child should perceive himself positively.

4. There is a need for further research regarding teacher attitudes toward the hearing-impaired.

\section{Attempts to Modify Attitudes Toward the Hearing-Impaired}

As discussed earlier, teachers' attitudes toward the handicapped can be modified. Further, most investigators imply that the best vehicle for modification might be inservice education. Research regarding modification of attitude toward the hearing-impaired as a singled-out handicap is extremely limited and appears void regarding teachers. Blake (1971) at the Hot Springs Rehabilitation Center, Hot Springs, Arkansas, assessed attitudes of entering students with normal hearing toward deaf and deafness and investigated the impact of integrating both groups in relation to attitude changes. A sample of 46 students with normal hearing was administered a pre-test, the Attitude to Deafness Scale (Cowen et al., 1967) and questionnaires. The treatment group received a variety of contacts with deaf students with varying lengths of contact time for eight 
weeks. Post-test analysis of attitudes were then analyzed. The- attitudes of the treatment group toward deaf and deafness became more positive. A high proportion of the hearing students became friends with deaf students; a significant proportion became interested in learning sign language; about one-fourth implemented finger spelling skills.

Blake's (1971) study supports the research by Anthony (1469) who tested the relationship of contact with disabled persons and the development of more positive attitudes. The Attitude Toward Disabled Persons Scale, Form A (Yuker, Block, \& Campbell, 1960) was administered as a pre-test to 42 non-handicapped summer camp staff members. Of the 42 staff members, 16 had been on staff at least one previous summer. The remaining 26 were new members to the staff. At the end of the camp session (a nine-week interval) a post-test, Form B, was administered. Results of this study exhibited the following:

1. Old staff reflected significantly more positive acceptance than did the new staff, both initially and after nine weeks of contact with the handicapped.

2. New staff exhibited significant positive attitude development at the end of nine weeks.

Thus, the investigators concluded that contact experience modified the subjects' attitudes toward the handicapped child. While contrary research does exist (Emerton \& 
Rothman, 1978) the limited research on attitude modification toward the hearing-impaired tends to support the fact that interaction with hearing-impaired persons contributes to attitude change.

The Need for In-Service Education Regarding Perceptions of the Hearing-Impaired

Davis, Shepard, Stelmachowicz, and Gorga (1981) exhibited concern that most regular classroom teachers have not received preservice course work which would enable them to understand or manage integrated, handicapped children. Hearing-impairment is one of the preponderant handicaps among mainstreamed children. An estimate of several million children in schools today have hearing losses, the majority of whom are placed in regular classrooms. The investigators surveyed 1,288 public school personnel of whom 874 (688) returned questionnaires. Included in the questionnaire were teacher perceptions of hearing-impairment effects on achievement and behavior and teacher needs for in-service training regarding that topic. The data indicated a need for thoughtfully planned in-service training for teachers receiving hearing-impaired students. Further, there appeared to be a need for knowledge of the role of amplification regarding the use of hearing aids. Also, more information was needed about modifying curriculum and academic achievement of the hearing-impaired. 
To be effective, the content of in-service training must be based on at least four pieces of information: (1) what is known about the characteristics of the impairment of concern; (2) general characteristics of the individual children to be served; (3) knowledge of the service delivery system involved; and (4) perceptions, background, and training of the population receiving in-service training. (Davis et al., 1981 , p. 176)

As a result of an investigation of attitudes toward deaf, Poulos (1971) suggested that in-service training should concern itself with changing behaviors to better accept the hearing-impaired and the development of more positive attitudes toward the hearing-impaired.

Germain (1975), Head Teacher for the Hearing Impaired, Fayette County Public Schools, Lexington, Kentucky, developed an in-service training mini-model. The goal was to encourage regular classroom teachers to view the hearingimpaired child as an enrichment factor to the school and as a challenge, not a problem. The developers of the model gathered the following teacher attitude data on which to base in-service workshop guidelines. (1) The teacher must realize that, initially, the work load will increase for a teacher who receives a handicapped child. (2) Recognize teacher individual differences as they relate to the hearing-impaired child. (3) Recognize that teachers have misconceptions about special classes.

Any approach for orienting teachers to children from special classes should reflect an awareness of these attitudes. Teachers who are selected must be those who are interested and who enjoy the 
diversity of their jobs. We mustn't burden them with extracurricular workshops and meetings; yet we should try to erase any fears or confusion by helping them understand more about hearing loss, convincing them that a specialist will always be available to help, and assuring them that they and their other students will have something to gain (p. 117).

The investigator suggested that an orientation session should be given to the receiving teacher and the session should include the following:

1. successful communication skills with the child;

2. understanding of relationship of language, speech, and communication;

3. recognition of individual differences in children; and

4. sounding-board for teacher questions.

The Project Director of the Title III Interdistrict Project for Hearing Impaired Children in Minneapolis in assessing negative attitudes suggested that those who plan in-service training "must recognize this attitude, respect it, remember it and develop materials to change it" (Seltz, 1973, p. 120). The investigator suggested the use of a multi-media approach would be more effective than just lecture. The content and format of the Minneapolis projects follows :

\section{1. $16 \mathrm{~mm} \mathrm{film}$}

This film covers physical, academic, and social problems a hearing-impaired child might encounter in a regular classroom. 
2. audio tape

This tape covers the strengths and weaknesses in using a hearing aid. A man's voice speaking through a hearing aid is recorded and depicts the problems encountered for understanding speech.

3. recording

This recording demonstrates how hearingimpaired children do or do not hear.

4. slide-tape

A demonstration of effective team-teaching of teacher, tutor, and specialist is presented.

5. slide-tape

Procedural adaptations such as preferential seating, monitoring of hearing aids, and effective use of visuals is presented.

6. discussion

Participants are encouraged to ask questions and to interact.

The investigator reported that participating classroom teacher responses suggest that the program has been effective in attitude changes and promoted an interest in program improvement for students with hearing-impairments. However, no statistical data were reported in support of these conclusions.

Seltz (1973) concluded that, regardless of what type of material is presented during an in-service workshop, the 
objective should be to develop a teacher whose attitudes will be positive and who will understand the needs of the hearing-impaired child.

Hopefully, the effect will be the provision of a realistic educational environment in which hearing impaired children can function effectively because the staff and students accept and respect them as regular members of the student body in their neighborhood schools (p. 126).

The purpose of in-service education should be to plan programs which further the professionalism of teachers through learning opportunities to improve performance. If in-service education is one of the viable answers to successful mainstreaming of the hearing-impaired, one must consider the effectiveness of the in-service sessions. What type of in-service workshops is most effective? Does workshop format and content make a difference in effectively modifying teachers' attitudes in a positive direction?

\section{Effective In-Service Workshop Sessions}

The development of an effective staff occurs when deliberate planning of recruitment, in-service education, and motivation of staff are implemented by the principal. In-service must answer the needs of individual teachers. Thus, teachers should be actively involved in selecting and planning viable sessions (Duke, 1982; Pederson, 1974; Joyce, MoNair, Diaz, Mckibbin, Waterman, \& Baker, 1977).

Ernst (1974) described characteristics of a good workshop, some of which follow: 
1. A good workshop meets a mutual goal of the learner and the in-service personnel.

2. A good workshop begins at the level of the learner and progresses toward the goal.

3. A good workshop should be presented at a convenient time and for an acceptable length of time.

4. A good workshop is designed to match the use of resources to the learning styles of the participant.

5. A good workshop allows the learner to gain strength and validation of objectives by interacting with colleagues.

6. A good workshop combines cognitive and affective objectives.

7. A good workshop encourages learners to interact honestly and openly.

Workshop goals should apply to daily classroom activities and meet the personal needs of the learner.

In-service education is a basic component on which teachers depend to extend their professional goals. The literature on in-service deals mainly with theory, case studies, and anecdotal summaries. There is a scarcity of experimental in-service which utilizes experimental and control groups (Orlich, 1982).

In-service education programs have received much criticism over the years. Hermanowicz (1966) surveyed 
teachers in twelve states and found that those teachers categorized in-service sessions as boring and unproductive. Many investigators reported that in-service programs are poorly planned and implemented (Brimm \& Tollett, 1974; Schild, 1964; Sharma, 1982; and Joyce, McNair, Diaz, McKibbin, Waterman, \& Baker, 1977). These reports reinforce previous statements of this investigation, that teachers need to be involved with planning in-service sessions. Incentives for teachers to participate in in-service education are widespread. Many teachers, despite many years of experience, do not feel equipped to teach all students. In ranking their reasons for involvement, 3,846 teachers responded that they wished to improve their teaching skills (Yarger, Howey, \& Joyce, 1980). McLaughlin and Marsh (1978) concurred. Table I describes the movitations of some teachers for participating in in-service education. 
TABLE I

MOTIVATIONS FOR ISTE PARTICIATION*

\begin{tabular}{|c|c|c|c|c|}
\hline Motivations & Urban/Rural & California & Michigan & Georgia \\
\hline \multicolumn{5}{|l|}{$\begin{array}{l}\text { Improved } \\
\text { teaching }\end{array}$} \\
\hline Certification & 4.1 & 3.2 & 2.9 & 8.5 \\
\hline Required & 8.4 & 15.9 & 27.1 & 22.0 \\
\hline Paid to attend & 4.3 & 0.5 & 0.9 & 0.8 \\
\hline Released time & 1.0 & 2.4 & 2.7 & 1.4 \\
\hline Salary Increments & 2.8 & 7.2 & 0.6 & 0.9 \\
\hline Degree Program & 5.0 & 2.4 & 2.4 & 8.3 \\
\hline Job activity & 9.8 & 7.9 & 5.6 & 8.0 \\
\hline Other & 5.4 & 7.0 & 15.5 & 6.9 \\
\hline Non-response & 4.8 & 3.7 & 2.3 & 4.1 \\
\hline Error & -- & -- & -- & -- \\
\hline \multicolumn{5}{|c|}{ *Source: Yarger, Howey, and Joyce, 1980 , p. B-13 } \\
\hline \multicolumn{5}{|c|}{$\begin{array}{l}\text { Gilchrist, Fielstra and Davis (1957) suggested that } \\
\text { in-service participation, to be effective, should be } \\
\text { voluntary. A stimulating environment elicits individuals to } \\
\text { work on skills which will be most beneficial to their }\end{array}$} \\
\hline
\end{tabular}




\begin{abstract}
When educators accept the assumption that improvement of instruction is possible only through continuous attention to curriculum development, and when there is an appraisal program by which teachers can determine their needs for in-service education, formal requirements are no longer so important. (p. 292)
\end{abstract}

Many in-service personnel feel that volunteer participation of teachers helps to individualize the sessions in that the teachers select in-service which best meets their specific needs (Wood, Thompson, \& Russell, 1981). Once participants have been invited to participate voluntarily, it is seen as good practice to inform the teacher's principal regarding the invitation. Thus, the principal could encourage the teacher to participate.

Principals are key people in school improvement and change; their encouragement of staff to participate in workshops, involvement in inservice with teachers, and assistance to teachers in follow up after training increase significantly the chances of real, lasting change in professional performance among the faculty. (p. 75)

The literature indicates that, with the implementation of PL 94-142, efforts to keep pace with mainstreaming have been difficult. In-service training can help teachers if those who provide the in-serivce consider adult learning theories and styles, use good planning and organization, devise effective delivery systems, and adapt the program to the size of the group. 
Adult Learning Theories and Styles Related to

In-service Education

McCarthy (1982) describes four major styles of learn-

ers: Type One Learners are concerned with personal meaning, are persons who are idea oriented, become personally involved, learn by listening and sharing, and function by interacting socially; Type Two Learners are concerned about information, are interested in what the experts think, seek facts, learn by thinking through ideas and enjoy traditionally designed classrooms; Type Three Learners want to try things for themselves, want to know how things work, test theories to learn, and draw inferences from sensory experiences; Type Four Learners wish to adapt their lives to take advantage of what they learn, seek hidden potentiality, learn by trial and error, and are at ease with people. Each learner perceives in $h$ is own way. Some sense and feel while others think or reason. After one perceives, he processes. Some proceed immediately while others watch and reflect. Table II indicates questions teachers ask to facilitate learners as they move through the stages of concern. 
TABLE II

QUESTIONS TEACHERS ASK AS THEY MOVE THROUGH THE STAGES OF CONCERN*

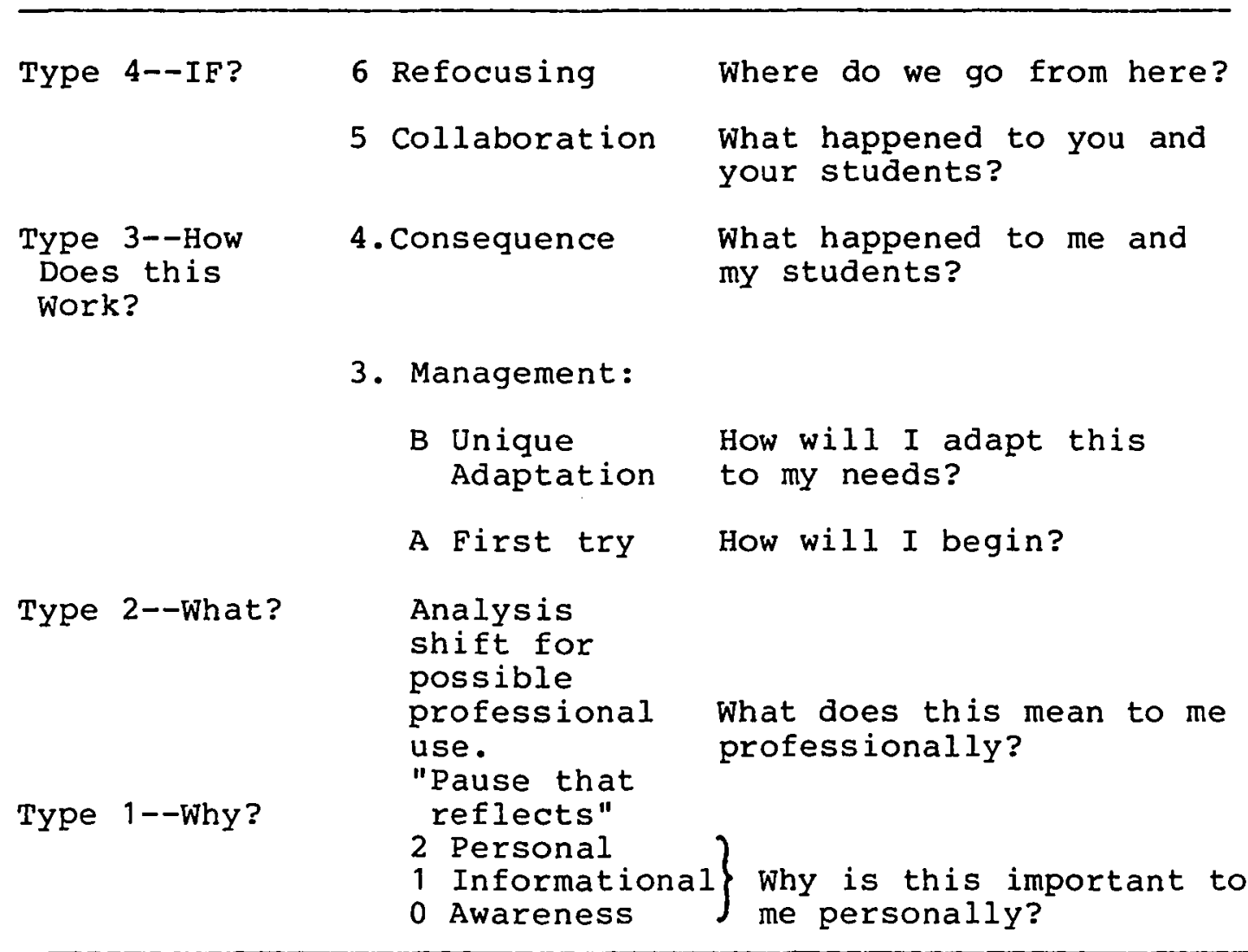

*Source: McCarthy, 1982, p. 25

Wilsey and Killion (1982) presented the following ideas "drawn from the work of Joyce (1980) and Bents and Howey (1981) and their interpretation of Santmire (1979)" (p. 36). 


Stage of Adult Development
Stage 1
Learners have a right-wrong orlentation to
situat lons. There is only one way, thelr
way, to view the world. Only when learners
perceive that what they are doing is not
working do they see a need for new know-
ledge. Information that does not fit the
learner's current bellef system is adapted
to fit categories that exist rather than
create new ones. These learners prefer
hlerarchical relationshlps. Practlcal
concerns about what to do in specific
situations (how would team learning work
in my second grade classroom?) are the
mafor focus for this type of learner.

Structure of the Training Environment
The learning environment must be highly structured. Presentation of practical information should emphasize (1) what to do, (2) how to do it, and (3) circumstances in whlch it should be done. Instructors should model. behaviors applicable in classroom settings including what to say to students and sample materials to be used. Several examples of how principles apply in specific situations need to be demonstrated. Outlines, handouts, and other support materlal should be organized in sequence to help learners focus on what is important. Discussions should include practical examples and applications rather than theory or generalizations. Ample time for consolldation and application of Ideas must be allowed. Follow-up is necessary for learners at this stage since they are often insecure in applying new learners and prone to abandoning ideas that do not work immediately. Follow-up assistance needs to be directive. Learners at this stage benefit from a supervisor who is wllling to tell them what to do and how to do it.

Stage 2

The training environment needs to provide cholces in content and Its presentation. Speciflc applications of ideas become a secondary focus rather than central to the presentation. Discussions that include various points of view relative to the issue should be concluded with a ratlonale of why the views are held. Follow-up assistance should be collaborative, allowing learners to express their opinions and suggest alternative actions.

Stage 3

Learners should be glven opportunitles to participate in the planning and delivery of

Learners at Stage 3 recognize that they have a variety of alternatives and can. choose the one that best fits the situation. They are able to accommodate contradlctory information by balancing or connecting differing Ideas. taff development programs. Tralning should include discussions that allow learners to share their viewpoints and experiences so that colleagues may learn from each other. 


\section{Stage 4}

Learners are able to synthesize informaton and create additional categories to accommodate new Information. They approach problems and situations in a systematic fashion, which enables them to quickly revlew alternatives in order to make effective, spontaneous decisions.
In this way learners are able to develop broader, more comprehensive perspectives. Follow-up assistance should be collaborative or nondirective. These learners benefit from active participation in identifying relevant issues and possible solutions.

\section{Stage 4}

These learners need an environment that allows them to work easily and comfortably in a varlety of ways. They should select and pursue toplcs of personal interest. Opportunities for critlcal and creative thinking should be avallable. Follow-up assistance should be nondirective, allowing these learners to design their own target and standards for achleving their goals.

Figure 1. Adult Learning Theory and Its Implication for Training. Source: Wilsey and Killion, 1980, p. 36. 
The forgoing ideas suggest characteristics for in-service as they relate to the various stages of adult learners. The characteristics are theoretical, but can be translated behaviorally. Thus, in-service programs should meet these behavioral needs which are related to adult learning styles. Santmire (1979) concluded that most adults (teachers included) belong to Level I and Transition to Level II. It thus becomes apparent that in-service should be oriented toward these levels. Level I learners look toward the practical. They can be threatened by change and tend to be defensive about innovations, especially if what they have been doing has been successful. Level I learners prefer to have new material presented by an authority. For effective in-service implementation, practical situations and specific orientation helps this learner to relate the in-service to their specific needs. Effective in-service for Level I learners should include lecture-discussion delivered by an authority figure. Transition to Level II learners have come to the realization that more than one process can accomplish the same goal. They begin to question authority. They prefer to develop their own approach to principles of interest. "Paradoxically, while these learners express a strong desire to do things on their own, they will need help in defining what they want to do and how to do it" (Santmire, 1979, p.. 25). Group discussion techniques in which learners could express their opinions would be 
effective in-service delivery for Transition to Level II learners. Lecture-discussion would also be effective if they could express their opinion and question the instruction model.

Developmental-task theories suggest that adults at specific ages and stages of life confront common developmental tasks.

Staff developers need to recognize the legitimacy of these age-related tasks and issues in their work. They need to investigate how the staff development programs they design can respond to and provide for teachers' continuing needs to 1) confront off-time events; 2) rework issues of identity, intimacy, generativity, and integrity; 3 ) negotiate life structure transitions; and 4) balance continued periods of transition and stability. (Oja, 1980, p. 16)

Developmental-stage theories assume that the development of humans proceeds from cognitive structure changes, which are the patterns of thinking a person utilizes to relate oneself to the environment. Authorities on these theories (Piaget, 1972; Kohlberg, 1973; Loeringer, 1976; and Hunt, 1975) "all posit a sequence of hierarchial, invariant, and qualitatively different stages with the higher stages being more adequate in the sense that they include taking multiple points of view, more empathetic role-taking, and more adequate problem solving" (Oja, 1980, p. 16). Developmental stages include cognitive development, moral development, ego development, and conceptual development. 
Oja (1980) suggested that staff developers of inservice education should acknowledge individual differences when planning specific programs. Developmental-stage theories and developmental-task theories suggest behavioral characteristics which in turn can be met through specific programming.

Chickering (1976) suggested that staff developers provide an authority figure to present information to teachers who are self-protective. Teachers who are conformists should be presented information via group discussions. Self-study programs should be offered these teachers who are conscientious. Lastly, for the teacher who is autonomous, self-defined goals should be supported. The categories of teachers who are self-protective, conformist, conscientious, and autonomous developed by Chickering follows very closely the stages of adult development discussed earlier in this investigation. The structure of the training is also very similar.

Dunn and Dunn (1979) described research which allowed educators to realize that perceptual strengths, also known as learning modes, develop differently among individuals. Between 208 and 308 of the population appear to be auditory--learn and remember what they hear. About 408 learn visually and 30-40\% are tactual/kinesthetic, visual/ tactual, or a combination of these four major senses. 
Duker (1965) generalized on the type of presentations which are most effective in meeting learning modalities. These generalizations resulted from an analysis of the interrelationship of written instruction and oral instruction from about 200 studies over a period of 60 years. Combining visual and auditory delivery tends to be more effective than using only one or the other. If material being presented is somewhat familiar to the participant, he is likely to learn more from an auditory delivery. If the material is unfamiliar, a visual presentation should be selected. Orie should consider two factors in designing a visual and/or oral presentation. These factors are ease of learning versus amount of retention. A visual delivery tends to favor ease of learning while retention seems to favor oral instruction. Should in-service education personnel consider sensory perceptual skills when planning instruction? Lecture/ discussion would tend to serve best those learners who are auditory. It becomes apparent that other learners could best be served through use of visuals and hand-on experiences. Current research suggests that adult learners differ in developmental variables. These differences relate to instructional designs for adults, such as in-service education and ultimately to learning and performance. 


\section{Planning and Organization of In-Service Education}

As discussed earlier, part of good in-service planning involves teacher involvement in selecting topics and organizing sessions, voluntary participation, and motivation. Also, in-service education should begin at the current developmental levels of the learners and progress toward the designed objective.

Joyce, McNair, Diaz, McKibben, Waterman, and Baker (1977) reported that other components involved with inservice planning are investigation of needs for in-service education, time of day and length of sessions, physical facilities, considerations of who should teach in-service, and design models.

Joyce et al. (1977) interviewed 1,016 educators who expressed a strong need for in-service education. Specific needs included further professionalism of teachers who are training in special-education and mainstreaming.

Dunn and Dunn (1979) reported that sitting still for long periods of time may inhibit learning. Harris (1980) suggested that sessions be no less than thirty minutes in length and not exceed four hours. Also, certain times of the day are peak energy periods for learning. Both of these considerations are unique to each individual. Joyce et al. (1977) discovered that some teachers prefer to participate 
in training during the regular school day while others do not want to miss class and contact time with their students. Who should be trainers for in-service education? Yarger, Howey, and Joyce (1980) reported that teachers believe that they are the best instructors for other teachers. At the same time, over half responded that they were not interested in serving as instructors. Joyce et al. (1977) in an extensive study recorded that over $20 \%$ of their respondents preferred university personnel, 208 favored teachers, and 158 selected consultants.

Where should in-service education be held? Harris (1980) concluded that physical facilities are an integral component of the planning. Space to accommodate use of equipment, size of group, use of tables when writing is required, to mention a few, are crucial for successful inservice activities. As simple as these seem, much chaos can be prevented by considering them important variables. Systematic approaches are believed to result in more effective in-service education planning and organization. Wood, McQuarrie, and Thompson (1982) developed a researchbased model for designing effective in-service education programs. The model is composed of five facets which incluade reaảiness, planning, training, impiểientation, and maintenance and is referred to as the RPTIM Model. The readiness component of RPTIM includes scrutiny of the school climate, goals, and practices as they relate to in-service 
needs. The facet of planning includes the needs of staff as they perceive their needs, examination of participants' learning styles, resources available, objectives of knowledge, skill and attitude development. The training component of RPTIM includes grouping learners, meeting individual needs, and selecting instructors. The implementation facet is composed of follow-up support activities, implementation of new learning, with supervision available from peers and administrators, and the availability of support resources. Lastly, the maintenance component of RPTIM includes the systematic monitoring and maintenance of new behaviors. The RPTIM Model was submitted to the regular membership of the Council of Professors of Instructional Supervision and the National staff Development Council in the form of a questionnaire. The results indicated strong support for all practices in the model. This model should help with designing effective in-service sessions based on what actually works rather than on opinion.

Joyce and Showers (1980) developed a set of components, based on analysis of 200 studies related to effectiveness of training methods, which made up their suggested effective training model. Used individually or in combination, these components effectively impact training. The components include: theoretical presentation or skill description; skill modeling and demonstration; simulated and 
classroom practice; constructive feedback; and support for application.

Lippitt and Fox (1971) developed an in-service training model composed of 11 dimensions.

1. needs for change identification

2. action-research projects

3. use of resource people

4. diagnosis of learning climate

5. use of change-agent teams

6. innovations in existence

7. resources of personnel

8. increased acceptance of in-service instructors

9. implications

10. peer support

11. siared results

These follow very closely the components cited by Joyce and Showers (1980). Collectively, the literature indicates that well organized and planned in-service education should result in the acquisition of a learned behavior, cognitive or affective, the understanding of the rationale underlying the behavior, and successful implementation of the behavior. Other conditions are delivery systems and group size.

\section{Delivery systems}

Allen (1971) concluded that activities implemented to attain behavioral performance should be very diversified. 
A wide variety of delivery systems provides effective training to meet individual teacher potential. Wood, Thompson, and Russell (1981) concurred that, because of varied learning styles, the well prepared in-service session should provide many different delivery systems. Harris (1963) determined that selection of in-service activities depends on the session objective, the number of feasible activities for a specific session, and consideraion of the effectiveness of activity sequencing. He identified 26 activities, or delivery systems. Harris further reported that all of these components can be important as a part of in-service sessions; however, some are little used. Some are more effective than others.

Harris and Bessent (1969) stated that of the 26 delivery systems discussed by harris (1963) some are more relevant than others in promoting changes in the learner. They advocated teacher involvement during in-service workshops rather than the passive receiving of information by the participants. They ordered the basic activities in a hierarchy as they relate to experience impact (Table III). They further concluded that the use of multisensory stimuli should probably increase the learning of participants.

Harris (1963) reported that illustrated lectures include passive involvement of the learners with the added stimuli of audio and visual components. The illustrated 
lecture includes the use of films, television, dramatization, and/or tape recordings. The lecture becomes most effective when it is illustrated and combined with small-group activities. The use of films and videotape recordings tends to elicit discussion activities. One must consider the group size. Large groups can view a film, but cannot easily discuss it nor interact.

TABLE III

EXPERIENCE IMPACT OF ACTIVITIES*

\begin{tabular}{|c|c|c|c|c|}
\hline Activities & $\begin{array}{l}\text { Control } \\
\text { of Content }\end{array}$ & $\begin{array}{c}\text { Multi } \\
\text { Sensory }\end{array}$ & $\begin{array}{c}\text { Two-way } \\
\text { communication }\end{array}$ & \multirow{3}{*}{$\begin{array}{c}\text { Low } \\
\text { Experience } \\
\text { Impact } \\
\uparrow\end{array}$} \\
\hline \multicolumn{4}{|l|}{ Lecture } & \\
\hline $\begin{array}{l}\text { Illustrated } \\
\text { Lecture }\end{array}$ & & $\mathrm{x}$ & & \\
\hline Demonstration & & $\mathrm{x}$ & & \\
\hline Observation & & $\mathrm{x}$ & & \\
\hline Interviewing & $x$ & & $x$ & \\
\hline Brainstorming & $x$ & & $x$ & \\
\hline $\begin{array}{l}\text { Group } \\
\text { Discussions }\end{array}$ & $\mathrm{x}$ & & $\mathrm{x}$ & $\downarrow$ \\
\hline Buzz Sessions & $x$ & & $x$ & $\underset{\text { High }}{\text { Higherience }}$ \\
\hline Role Playing & $\bar{x}$ & & $x$ & Impact \\
\hline $\begin{array}{l}\text { Guided } \\
\text { Practice }\end{array}$ & $\mathrm{x}$ & & $x$ & \\
\hline
\end{tabular}

*Source: Harris and Bessent, 1969, p. 35 
The use of videotapes has excellent potential and should be considered for in-service sessions. Dailey and Halpin (1981) used videotapes to try to modify undergraduate students' attitudes toward the handicapped. The purpose of their study was modification of attitudes through observation of videotapes of handicapped children. Video or non-video treatment sessions were randomly assigned to 52 students. The video treatment had significant positive effects on the students' attitudes toward the exceptional children. Implications from the study suggested more use of videotapes in preservice and in-service education.

Donaldson and Martinson (1977) conducted a study using 120 nondisabled students in an introductory psychology class to differentiate the effects of video presentations of handicapped persons, panel presentation of handicapped persons, and a tape recording presentation of disabled persons. Results indicated that subjects who viewed videotapes and the panel presentation significantly improved their attitudes more than those who were presented only audio tapes and the control group. "The effectiveness of the videotaped presentation suggests a technique that is relatively simple, short term, and feasible for widespread application in modifying prejudices toward the disabled" (p. 341$)$.

DeVault, Houston, and Boyd (1962) reported, in a study designed to evaluate the relative effectiveness of 
television, lecture-discussion, and each supplemented with consultant services, that a variety of delivery systems is important.

Levine and Butler (1952) reported lecture produces limited changes in behavior. Lectures are more effective when used for transmission of knowledge. Lectures have been poorly accepted over the years due to poor and unsuccessful attempts to change attitudes and behaviors. Lectures need to be carefully planned, organized and illustrated through audio-visual supplements (Dietrich, 1960).

Donaldson and Martinson (1977) reported that the use of discussion may develop positive attitudes. Harris (1963) also believed that discussion groups contribute greatly to improving understanding of an objective. Harris and Bessent (1969) reported that discussion groups provide a foundation on which action groups can operate. Discussion as a technique elicits stimulating thought processing of complex problems. This, in turn, can influence opinions and attitudes. Hill (1960), in a comparison of lecture and discussion methods, reported that lecture should be reserved for transmission of knowledge, while discussion groups lend themselves more effectively for developing human relations and interventions.

Janis and King (1954) conducted a study at Yale University in which they researched the influence of role playing on opinion change. They selected subjects to give in- 
formational talks based on highly biased but logically relevent outlines of written material prepared by the experimenters. Each active participant was to play the role of a genuine advocate of the given point-of-view while two others listened to the talk and read the prepared outline. All active participants were to argue in favor of a position which differed from their initial beliefs as reflected earlier on an opinionnaire. The results indicated that role playing can significantly influence the acceptance of new beliefs. The active participants who advocated a particular position tended to be more influenced than were the passive controls who listened to the presentations.

The influence of role playing has been tested in other settings. Clore and Jeffery (1972) conducted an experiment exploring the effects of role playing on attitudes toward the disabled. The role playing in their experiment consisted of one group of individuals traveling about a college campus for an hour in a wheelchair. A second group of subjects were asked to observe the role players' experiences. Results from an analysis of variance on the survey of attitudes toward disabled students yielded significant immediate and long-term effects of positive attitude change. Gilchrist, Fielstra, and Davis (1957) believed that in-service education ought to relate to on-going school programs and problems so that the in-service activities can be tested in the actual classroom. In several cases, 
teachers were asked to role play several problems of concern to teachers, such as discipline. After the role-played presentations, the teachers discussed the implications and became interested in the use of the same techniques in the classroom.

Harris (1963) reported that role playing is well suited for in-service sessions which deal with problems regarding human relations. Involvement in role playing suggested high experience impact for attitude development. Role playing is usually accepted by most participants and stimulates much interest. Role playing theorists, Janis and King (1954) and Sarbin and Allen (1964) determined that the technique of role playing is an effective catalyst of positive attitude and behavior change.

Mckalip (1979) realized that the need of acceptance and the need to belong are high on the list of human needs. People need to realize that humans have similarities and differences and this fact in itself is acceptable. Role playing causes one to consider how they would feel if they actually owned the difference that had been dramatized. Simulation is used when true-to-life situations are not available. Conditions under simulation can be very structured and similar to first-hand experiences. Participants who simulate an activity should sense the reality as they proceed (Harris \& Bessent, 1969). The concept of simulation when used for in-service sessions is best 
defined as "utilizing actual reality with sufficient structure to simplify rather than to imitate" (Harris, 1980, p. 265). Harris (1980) further suggested that simulations offer a vast variety of manipulative experiences for learning. Types of simulation involve role playing, situational simulations, and games.

Yates (1973), in search of an effective in-service model, researched the use of laboratory experiential design, often referred to as simulation. His results indicated that the laboratory experiential model increased teachers' perceptions of handicapped students. Coleman (1976) suggested that in the primary grades much experiential learning is utilized. Unfortunately, the use of this technique diminishes and is replaced by lectures, discussions, and other techniques in the upper grades. Coleman (1976) also believed that much adult learning requires practice and experience. Experiential learning should be considered at all levels of learning.

Wilson and Alcorn (1969) studied the relationships between simulation of a disabling condition and changes in attitude. Participants were assigned to live with a simulated disability for an eight-hour period. Conditions simulated were blindness, deafness, loss of dominant hand, and loss of lower limbs. Results indicated a slight, insignificant difference between those who simulated an experience and the control group. Reid, Reid, Whorton, and Richard (1972) 
studied the use of extensive contact experiences in special education classrooms. The results of their study suggested that contact with exceptional children should be incorporated in teacher-training programs. Wood and Neill (1978) assessed the effects of clinical workshops which involved experiential learning. They reported that the use of direct experience has many positive implications for improving inservice education.

In summarizing effective delivery systems for in-service education, researchers reported that active involvement has the greatest impact regarding learning (Harris, 1963). Hunter (1971) believed that ideally the learner should be actively engaged in pursuing an objective. A learner who is active is more likely to learn or change a behavior than the passive learner who sits back and hopes changes will occur. Watts (1967) examined opinion change induced by active participation. Requiring participants to write (active) an argument compared to those who read (passive) a persuasive message resulted in superiority of the active-participation conditions.

\section{Group Size}

Choice of delivery systems is related to the size of the group. Kelley (1951) determined that an efficient, effective group size is made up of eight to twelve people. The Institute for Development of Educational Activities (I/D/E/A) held that the use of the small group is becoming 


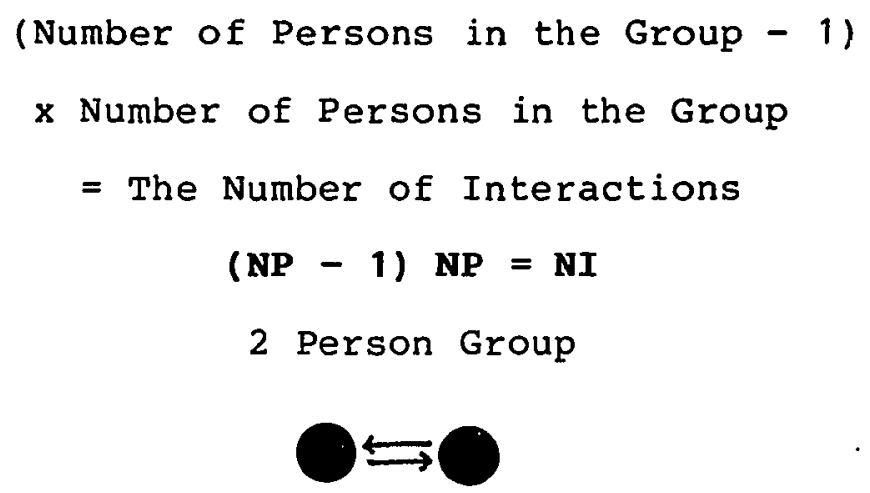

$(2-1) 2=2$ Interactions

3 Person Group

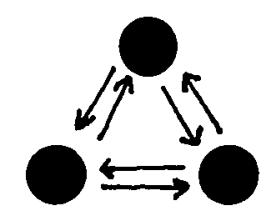

$(3-1) 3=6$ Interactions

4 Person Group

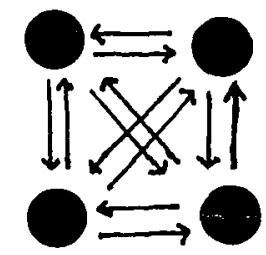

$(4-1) 4=12$ Interactions

Figure 2. Formula for Group Interaction. Source: I/D/E/A/, 1971, p. 11 
increasingly important in a variety of professions ( $I / D / E / A$, 197.1). See Figure 2. Learning in the small group can be used as an independent process as well as supporting other modes of teaching and learning. The small group process elicits dynamics and stimulation for attaining learning behaviors. Usually leaders as well as participants become more intellectually involved in the small group situation. More student involvement would evolve if the leader relinquished his traditional central role in the group and became an associate with the learners. The group size must be small enough for survival of individual needs yet large enough so that a variety of persons interact and stimulate one another. The researchers of $I / D / E / A$ believed that five to eight is an effective group size. They based their group size on a formula related to group interaction. As the group size increases the number of interactions intensifies. Figure 3 shows how group size relates to the type of activity selected and the impact of that activity: In summary, as group size increases impact of experience activities decreases. Group size can decrease independent of activity impact. Larger numbers of learners might be served by dividing them into smaller groups. Activities in the middle range of the hierarchy are the most flexible for adaptation to group size. Impact of the highest level delivery systems requires small group or individual involvement (Harris, 1980). Rehage (1959) reported that 


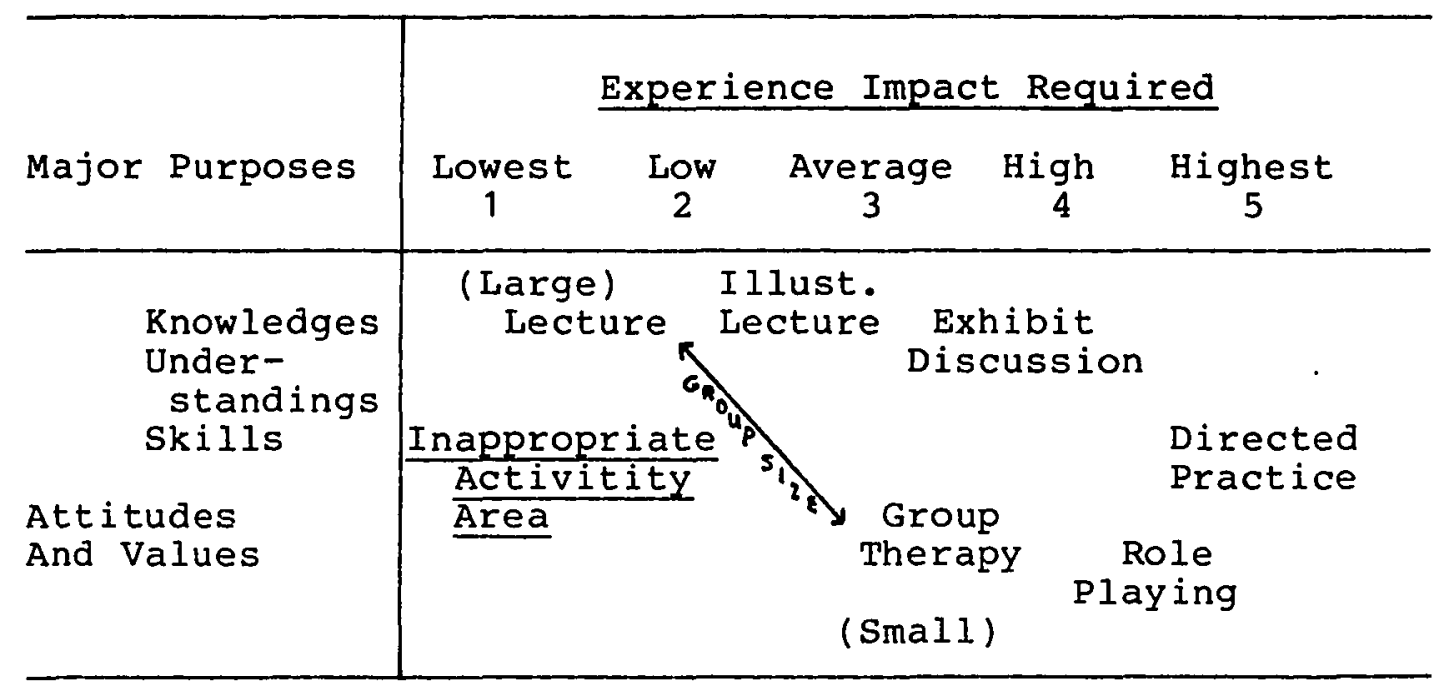

Figure 3. Selected Activities Arranged by Purpose, Experience Impact Required, and Group Size. Source: Harris, 1963, p. 74 .

teachers who responded to a questionnaire regarding in-service education implied that small group arrangements were valuable.

Summarizing effective in-service education components, Wood and Thompson (1980) recommended inclusion of 1 ) participant control over the topic and objective pertinent to their needs, 2) provision of a variety of choices to meet individual differences and needs, 3) provision of simulated and/or real work settings, 4) small group participation, and 5) use of peer evaluation and feedback upon implementation of the objective. 


\section{Effective In-Service Workshops Relevant to the Handicapped}

Paul, Turnbull, and Cruickshank (1977) provided specific objectives for planning effective in-service sessions regarding the handicapped learner. They cautioned that attitudes, fears, and feelings are not quickly erased nor quickly replaced with more positive responses toward handicapped children. "The important thing however, is that attitudes do change and can be helped to change more rapidly if constructive measures are taken through wellconceptualized in-service education" (p. 113). They suggested that orientation to the specific handicapping condiiions sensitizes participants to specific problems. For example, many educators view all persons who have a hearing loss as "deaf." The hearing-impaired children and adults today continue to be plagued with the term "deaf and dumb." The orientation component of a workshop should present an overview of the exceptionality or exceptionalities to be covered in the session. A second component should be content--knowledge of the nature and needs of exceptional children. They recommend that this is best done through discussions and illustrated lectures. Lastly, the in-service must be well planned and organized.

Haring, Stern, and Cruickshank (1958) attempted to modify teachers' attitudes through the use of workshops. 
Several of the basic purposes of their study included 1) determination of workshop influence in a positive direction, 2) effective workshop structure and 3) extent to which workshops can change behaviors. The structure of their workshop included a length of two hours designed to provide one hour of lecture to the total group and one hour of free discussion to small groups not to exceed 18 teachers on the topic of eight areas of exceptional children. The objective of the lectures was increased knowledge and understanding of exceptional children. The discussions were unstructured and the objective was for teachers to discuss their attitudes toward children. Included in the study was the opportunity for teachers to make one-half day visits to a special classroom, residential school, private school or clinic in which exceptional children were enrolled. To measure the effectiveness of these workshops a battery of four tests were administered to the participants. These tests measured knowledge and acceptance of exceptional children and personality characteristics of the teachers. The results of the study showed that workshops strongly influence the development of positive attitudes toward exceptional children. The implications are that the workshop objective would be a positive modification of attitudes through orientation of the disabiity and knowledge and understanding regarding the disability. Lastly, the delivery system might 
include moderately sized groups, use of consultants as lecturers, discussions, and observations.

\section{Effective In-service Workshops Relevant to the}

Hearing-Impaired

Seltz (1973) believed that the first objective in planning in-service training for the hearing-impaired is to determine the intended audience. Will the participants be regular classroom teachers, special education teachers, or administrators? Next, one should consider the length of the sessions in relation to the content and format. It was suggested that, to make the in-service interesting and effective, one should use a multi-media delivery system, rather than a straight lecture. The use of films, records, videotapes, tapes, transparencies and slide-tape shows are recommended, followed by group discussions. The model seltz designed was a two and one-half hour program presented in two sessions. It was designed for a Title III Project and included a 30-minute film which was a thorough coverage of classroom situations of potential difficulty for a hearing-impaired student. A tape recording of speech sounds through a hearing aid was also included. The third component was a tape recording demonstrating how children with varying degrees of hearing loss perceive speech. Next, a slide-tape presentation defining teacher, clinician, and tutor responsibilities was proposed. Lastly, a slide-tape 
show, demonstrating procedures such as monitoring of hearing aids or preferential seating, was included. The investigator felt that if this structure were followed by participant interaction of mutual concerns, the in-service would be effective and successful. Regardless of the content or format, the focus should be on developing positive attitudes toward the hearing-impaired student.

Yater (1977) believed that school in-service for regular classroom teachers who are to receive hearing-impaired students should include an orientation to familiarize teachers with the handicap and to alleviate anxieties. General information should be presented through tapes, filmstrips, or films. Specific information should be presented on topics including hearing loss, hearing aids, speechreading, and classroom adaptations. The investigator suggested that a demonstration of the various types of hearing aids be presented. Demonstrations of speech reading difficulties should be more impacting than merely talking about them.

In 1972 Yater developed a hearing clinician program for St. Louis County, Missouri, Special School District. To elicit better working relationships between clinicians and regular classroom teachers, she suggested topics cover 1) teaching aids, 2) oral correction of homework, 3) lip reading, and 4) hearing aids, to name a few. 
Nober (1975) developed the HI-FI program (Hearing Impaired Formal In-Service) to be used as the basis for inservice training to faciliate integration of the hearing-impaired child into the regular classroom. These materials consist of a manual, a set of transparencies, an audio cassette, and a videotape recording. The program was designed for classroom teachers, personnel, and parents. Bitter and Johnson (1974b) developed Systems O.N.E. (Orientation to the Normal Environment) as an in-service program to meet the needs of helping classroom teachers integrate hearing-impaired students into regular classrooms. The program contains one introductory booklet, nine filmstrips, nine cassette tapes and nine guides on the following topics: language, clasroom management, peer orientation, classroom communication, family orientation, speech, administrative guidelines, and hearing aids. For an effective program, a knowledgeable person is needed to assist with discussions which follow each sound-filmstrip. Probe questions for discussion are included in the guides. The program also includes flexible ways to use and to supplement the sound-filmstrips.

In-service education designed specifically for the topic of the hearing-impaired should follow the same guidelines as any effective program, as well as specific information regaring an orientation and a knowledge base to under- 
stand the feelings and behavior of the child who has a hearing loss.

\section{Summary}

Greenum (1958) contended that educators must understand that loss of hearing is not only a physical handicap but also a social handicap. If this handicap is not understood and accepted, social stigmas will develop regarding the self-concepts and productivity of handicapped children as important persons in our society. It is impossible to expect hearing-impaired persons to make all of the adjustments to society. Normal hearing persons must make an equal effort. Poor attitudes are usualy based on a lack of understanding the handicap.

In her review of literature regarding attitudes and mainstreaming, Horne (1979) concluded that handicapped students are usually assigned lower status positions in our society. Professionals, families and peers can be re-educated for the purpose of changing their attitudes and acceptance of the handicapped. Rejection of the handicapped may stem from adults in the school. Knowledge and experience bases should be designed for classroom teachers to develop positive attitudes toward the handicapped.

Returning the handicapped child to the regular classroom will enrich his environment. Normal children will profit by working with these peers and the handicapped will, 
through mutual acceptance, contribute positively to our society (Yater, 1977).

As we continue our teaching effectiveness experiments, and as we continue to probe teachers' thinking about behavior change, it should be possible to tailor the length and intensity of in-service training to the types of practices being recommended and the teachers' reactions to those practices. (Mohlman, Caladarci and Gage, 1982 , p. 35)

Harasymiw and Horne (1976) concluded that experiences such as in-service workshops can be used to modify attitudes. Effective in-service education should be based on the needs of the learners, meet the learning styles of the participants, and should meet the objective of developing positive outcomes through substantive knowledge and understanding, both cognitive and affective (Wood, Thompson, \& Russell, 1981).

Attitudes can be changed. Attitudes toward specific handicaps can be directed toward a positive acceptance. The phenomena of modifying attitudes should not be left to chance. Re-education of persons with negative attitudes should be well planned and organized (Emerton \& Rothman, $1978)$. 
CHAPTER III

METHODS AND PROCEDURES

\section{Introduction}

The preceding chapter indicated that teachers' attitudes can be modified, and there is a need to modify regular classroom teachers' attitudes to receive mainstreamed handicapped children into their classroom with positive feelings. The review of the literature revealed that among the handicaps, the status of the hearing-impaired was on the lower end of the hierarchy of those exceptional children teachers preferred to receive into their classrooms. Also, the literature review indicated that an effective vehicle for modifying attitudes was the use of in-service education workshops. Although there was a lack of research-based statistical evidence regarding the effectiveness of the in-service education workshops, the resulting challenge was to design a study which would provide a statistical test of the effectiveness of these workshops.

The remainder of this chapter is devoted to the methodology and procedures of this study. Succeeding sections will describe the research design, instrument selection, procedures for the selection of a sample, data 
gathering procedures, design and implementation of the workshops, the statistical design, and the hypotheses.

\section{Research Design}

An experimental design was selected using a stratified random sample of participants. The levels of the independent variable were: an active involvement, in-service workshop; a passive involvement, in-service workshop; and a no workshop control group. Subjects were randomly assigned to the workshops (active involvement or passive involvement) and the control group. Thus, the comparison group design was made up of three groups. A pre-test was not administered due to the possibility of contaminating the investigation. It was reasonable to expect that the control group would be comparable as a result of the random assignment of the participants. The dependent variable was teachers' attitudes toward the hearing-impaired student. The criterion measures were two post-tests, administered immediately following the workshop presentation. For control purposes no debriefing was administered at the end of a workshop, as teachers returned to buildings where others might be attending subsequent sessions. Each presentation included an observer who evaluated the presentation for consistency in workshop delivery (Appendix A). 


\section{Instrument Selection}

The selection of an instrument was based on those tests (Glass \& Meckler, 1972; Haring, Stern, \& Cruickshank, 1958; Cowen et al. 1967; Blake, 1971; Kvaraceus, 1956; Siller et al., 1969; \& Poulos, 1971) discussed in Chapter II. Because the purpose of this study was to attempt to modify teachers attitudes toward the hearing-impaired, the Attitudes to Deafness Scale by Cowen, Bobgrove, Rockway and Stevenson (1967) was selected because of its specificity to the topic compared to the others (Appendix B). This 25-item test utilizes a 4-point Likert scale and deals with attitudes toward deaf people in general. It does not test attitudes toward hearing-impaired children specifically. The test has a corrected split-half reliability of .83 . The mean for the field tested sample for this test was 51.02 with a standard deviation of 7.32 .

The literature search suggested that no test was available specifically to determine teachers' attitudes toward hearing-impaired students. The investigator developed the Teacher Scale of Attitudes Toward the Hearing-Impaired Student (Appendis C) from 34 test items (Appendix D) designed by the investigator with the help of a recognized expert. The scale items were designed to test for a relationship between behaviors and attitudes. Ihis 
would support and expand the studies discussed in Chapter II by Wandt (1952), DeLeo (1976) and Vacc and Kirst (1977) who found that a relationship existed between attitudes and behaviors of teachers who worked with Educable Mentally retarded students and emotionally disturbed students. The scale items were designed to measure teacher attitudes toward the classroom behaviors of hearing-impaired students.

It was anticipated that the resulting score would predict how well a teacher would interact with hearing-impaired pupils and indicate possible in-service education needs for programs designed to modify teachers' attitudes toward the hearing-impaired student. The common behavioral problems of hearing-impaired children in regular classrooms, as perceived by the investigator and a recognized expert, Dr. H. William Brelje (Note 1) were used to compile a pool of possible scale items (Appendix D). In a second examination of the 34 items by a recognized expert and the investigator, items three and nine were eliminated because they were more factual than attitudinal. Items 15 , $18,22,27$, and 31 were eliminated because of confusing terminology. Item 20 was eliminated because of a conflict between what is factual and what is reality. Item 34 was eliminated because students would tend to adopt their teacherș' attitudes. A second recognized expert, Dr. Carolyn Bullard (Note 2), confirmed this refinement of the instrument. 
The revised scale (Appendix C) of 25 items, utilizing a 4-point Likert format, was field tested with 53 undergraduate elementary education majors. These students were declared majors who were seeking regular elementary classroom teaching certification. For test reliability the responses of the 53 field test participants were tabulated and submitted to the SPSS subprogram, RELIABILITY. The model used was ALPHA (Hull \& Nie, 1981). The resulting item-total coefficients and the coefficient of reliability are shown in Table IV. Two reliability coefficients are computed for alpha, Cronbach's "a" and a coefficient labeled standardized item "a." This test for internal consistency yielded an alpha of .85345 (Table IV).

The Teacher Scale of Attitudes Toward the HearingImpaired student specifically tests situations that would be common-place frustrations of regular classroom teachers receiving and ultimately mainstreaming hearing-impaired children. The term hearing-impaired in the title of the scale was selected because of the status overtones and misconceptions connoted by the term deaf. Also, the title was not listed on the test so teachers would not be alerted to the attitude facet and consequently answer how they thought they should rather than reflecting their true feelings. 
TABLE IV

COEFFICIENTS OF CORRELATION AND COEFFICIENT ALPHA FOR THE TEACHER SCALE OF ATTITUDES TOWARD THE HEARINGIMPAIRED STUDENT

\begin{tabular}{|c|c|}
\hline Question & Item-total Correlations \\
\hline $\begin{array}{l}Q 1 \\
Q 2 \\
Q 3 \\
Q 4 \\
Q 5 \\
Q 6 \\
Q 7 \\
Q 8 \\
Q 9 \\
Q 10 \\
Q 11 \\
Q 12 \\
Q 13 \\
Q 14 \\
Q 15 \\
Q 16 \\
Q 17 \\
Q 18 \\
Q 19 \\
Q 20 \\
Q 21 \\
Q 22 \\
Q 23 \\
Q 24 \\
Q 25\end{array}$ & $\begin{array}{l}0.39004 \\
0.32453 \\
0.62557 \\
0.38463 \\
0.40671 \\
0.54198 \\
0.53062 \\
0.25290 \\
0.41730 \\
0.30972 \\
0.33448 \\
0.45140 \\
0.37917 \\
0.51650 \\
0.39522 \\
0.50675 \\
0.41251 \\
0.41577 \\
0.31302 \\
0.38360 \\
0.44069 \\
0.28403 \\
0.31652 \\
0.54497 \\
0.19410\end{array}$ \\
\hline & ALPHA $=0.85345$ \\
\hline
\end{tabular}




\section{Sampling and Sampling Procedures}

A suburban school district was selected for several reasons. It mainstreams children who are hearing-impaired. Thus, it represents a population of regular elementary classroom teachers who could, in the future, conceivably receive hearing-impaired students even though the regular classroom teachers are not required to nave had any special education training. The district was also selected because it is believed to be a district whose administrative personnel are open to research and implementation of successful programs. The district integrates university and college students and faculty into their professional realm for preservice and in-service training of educators. The school district furnished the investigator of this study a computer print-out of the regular elementary teachers. The print-out was divided by primary grades one, two; and three and intermediate grades four, five, and six. The teachers selected for the study were full-time, regular elementary classroom teachers. To assure equal representation from both primary and intermediate levels, equal numbers of teachers were selected from each of the two categories. The list of teachers of grades one, two, and three were consecutively numbered 1-213. Using a table of random numbers, three groups of 15 teachers were selected. As the numbers were selected, the teacher was assigned one, two, or 
three in that order until there were 15 ones, 15 twos, and 15 threes. Number ones were assigned to the control group, number twos were assigned to the active involvement group and number threes were assigned to the passive involvement group.

The list of teachers of grades four, five and six was consecutively numbered 1-204. Using a table of random numbers, three groups of 15 teachers were randomly selected. As the numbers were selected, the teacher was assigned one, two, or three in that order until there were 15 in group one, 15 in group two, and 15 in group three. Number one group was assigned to the control group, number two group was assigned the active involvement group, and number three group was assigned to the passive involvement group.

In both cases a reserve pool was selected during the intial selection process for each group. Besides the 45 teachers in each group of primary and intermediate participants, an additicnal 60 were selected in each group as the reserve pool. These were listed in the order selected so that if a person declined to participate the next person in line was assigned to that group. That person had also been assigned a one, two, or three for treatment purposes and the appropriate person was assigned the opening. Thus, there was a pool of 60 primary teachers divided into 20 for the control group, 20 for the active group, and 20 for the 
passive group. Likewise, the pool of intermediate elementary teachers numbered 60 and was divided into 20 for the control group, 20 for the active group, and 20 for the passive group (Table V).

The first letter to be sent regarding the workshops and the study was sent by the deputy superintendent. He informed the building principals about the study and asked them to encourage the teachers to take part (Appendix E). of the first 90 names randomly selected, 60 were sent letters (Appendix F) inviting participants to take part in workshops to be held on a teacher workday. Their participation was encouraged by indicating they would gain knowledge regarding the hearing-impaired if they took part, and they would be given consultation time in the future if they requested it. The teacher work day was a day scheduled

TABLE V

SELECTION OF PARTICIPANTS

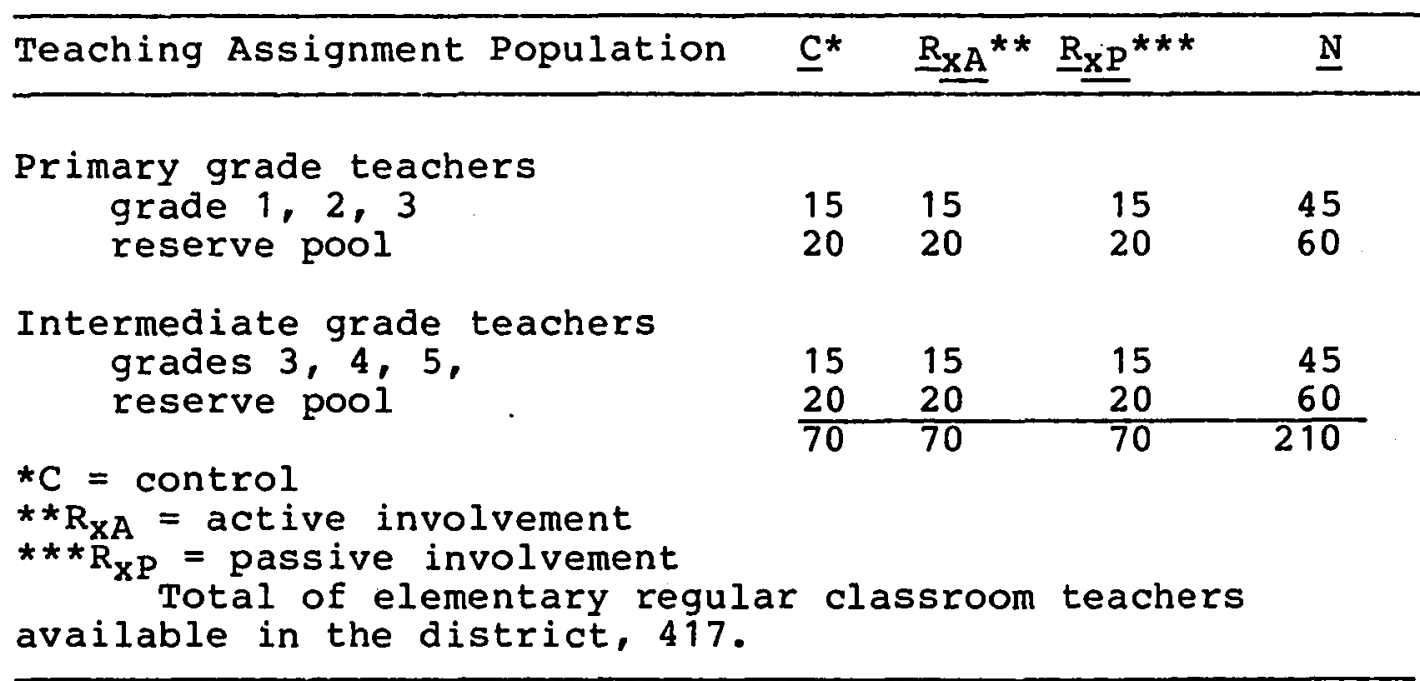


without children in attendance so teachers could prepare parent conferences. The remaining 30 teachers were sent a letter (Appendix G) inviting them to rate an attitude scale. Return addressed envelopes and response notes were included with the letters (Appendix H). Of the 30 teachers invited to participate in the control group 27 responded positively. Three did not respond (Table VI).

of the 60 teachers invited to participate in workshops on the teacher work day, 8 responded positively to the morning session, an active participation workshop. None offered to attend the afternoon session, the passive involvement

TABLE VI

INITIAL RESPONSES OF SAMPLING

\begin{tabular}{|c|c|c|c|c|}
\hline Group & Letters sent & Yes & No & No Response \\
\hline Control participant & 30 & 27 & - & 3 \\
\hline Active participant & 30 & 8 & 8 & 14 \\
\hline Passive participant & 30 & 0 & 12 & 18 \\
\hline $\begin{array}{l}\text { Total } \\
\text { Percent of Total }\end{array}$ & 90 & $\begin{array}{l}35 \\
38.8\end{array}$ & $\begin{array}{l}20 \\
22.2\end{array}$ & $\begin{array}{l}35 \\
38.8\end{array}$ \\
\hline
\end{tabular}

session. None of the teachers contacted were aware of the kind of group they had been assigned to. Of 90 letters sent a total of 35 , or 38.88 , agreed to participate. An additional 20 responded that they did not wish to participate. Of these 20,15 stated reasons which indicated they 
needed the day for working on parent conferences, five gave no reasons. Thirty-five or 38.88 , did not respond at all (Table III). Because of the poor response for workshop participation and because reasons, when given, for not participating was the need for the workday and not enough time, a second letter (Appendix I) was sent to the 15 who wanted to work in their classrooms and to those 35 who had not responded. The five who did not give reasons and indicated they did not wish to participate were not contacted. The three who did not respond to the survey only, or control group, were not contacted. The second letter encouraged the teachers to reconsider by announcing the workshop would be one hour long instead of two and gave them a choice of two dates at two different schools. The schools were located at two different ends, east and west, of the district for convenience of driving time. Those randomly selected for passive involvement workshops were given two alternative dates, nine days apart, at the two locations. Those who had been selected for the active involvement sessions were likewise given two alternative dates, nine days apart, at the two locations. Return addressed erivelopes and response notes were included with the letter (Appendix J). The dates selected were also four different days of the week. The investigator sent a letter to each principal requesting his or her help. The principals were also sent a copy of the letter their 
teachers were to receive so they would be knowledgeable about the inservice workshop dates and purpose (Appendix K). The purpose was presented in quite general terms so as to not alert principals or teachers of the specific nature of the study.

In the second request to 40 of the initial 90 teachers selected, 12 of those scheduled for active involvement responded yes, 13 of those scheduled for passive involvement responded yes, 15 did not respond (Table VII).

TABLE VII

SECOND RESPONSE OF INITIAL SAMPLING

\begin{tabular}{lrccc}
\hline Group & Letters sent & Yes & No & No Response \\
\hline Control participants & 0 & - & - & - \\
Active participants & 18 & 12 & - & 6 \\
Passive participants & 22 & 13 & - & 9 \\
\hline Total & 40 & 25 & - & 15 \\
Percent of total & & 62.5 & - & 37.5 \\
\hline
\end{tabular}

The investigator next drew names from the reserve pool of random names selected. There were three vacancies for the control group, 10 vacancies for the active involvement group, and 17 vacancies for the passive involvement group. A total of 30 participants was needed for the original target of 90 . 
The investigator decided not to request teachers to fill the three openings in the control group. Since the original three had not responded the investigator decided to contact them in their respective buildings when administering the scale to those who had agreed to participate. Ultimately, this strategy worked and the three participated.

There were 10 vacancies for the active involvement group. The investigator used the 20 names from that reserve pool and sent a letter to those persons requesting their participation. A response sheet and return addressed envelope was included (Appendix L). The same process was used to fill the 17 vacancies for the passive involvement group (Appendix $M$ ).

In the third request to 40 teachers from the reserve pool, 9 teachers responded yes to the active involvement group and 14 teachers responded yes to the passive involvement group, and 17 did not respond (Table VIII).

TABLE VIII

REQUESTS FROM RESERVE POOL

\begin{tabular}{lcccc}
\hline Group & Letters sent & Yes & No & No response \\
\hline Control participants & - & - & - & - \\
Active participants & 20 & 9 & - & 11 \\
Passive participants & 20 & 14 & - & 6 \\
\hline Total & 40 & 23 & - & 17 \\
Percent of total & & 57.5 & - & 42.5 \\
\hline
\end{tabular}


Thus, a total of 83 teachers committed themselves to the study through request letters and responses and three responded when the investigator approached them in their respective buildings for a final count of 86 teachers responding (Table $I X)$.

TABLE IX

TOTAL PARTICIPANTS IN STUDY

\begin{tabular}{|c|c|c|}
\hline Groups & Date & $\begin{array}{l}\text { Number of } \\
\text { Participants }\end{array}$ \\
\hline *Control (Teaching sites) & $4 / 1-4 / 15$ & 30 \\
\hline \multicolumn{3}{|l|}{$\begin{array}{r}\text { Active involvement } \\
\text { Administration }\end{array}$} \\
\hline Building & $4 / 9$ & 8 \\
\hline Montclair & & \\
\hline School & $4 / 20$ & 10 \\
\hline Aloha Park & & \\
\hline School & $4 / 29$ & 11 \\
\hline Total Group & & 29 \\
\hline \multicolumn{3}{|l|}{$\begin{array}{c}\text { Passive involvement } \\
\text { Montclair }\end{array}$} \\
\hline School & $4 / 9$ & 14 \\
\hline $\begin{array}{l}\text { Aloha Park } \\
\text { School }\end{array}$ & $4 / 28$ & 13 \\
\hline Total Group & & 27 \\
\hline
\end{tabular}




\section{Data Collection}

The 86 participants for this study were randomly assigned to three groups. Data for the control group was collected, followed by the administration of workshops and collection of data for the passive and active involvement groups.

\section{Control Group}

The control group had received in their letters (Appendix G) specific dates and times the investigator would visit their school to administer the two attitude scales (Appendix $B$ and $C$ ). The letters had been sent prior to spring vacation. Responses were requested before spring vacation, also. Thus, the data collection began the second week after spring vacation. This allowed the teachers a week of adjustment to their classes and any changes in their schedules. The investigator visited each of ten buildings over a two-hour period which included a recess break, a lunch break and scheduled breaks such as music, physical education and/or library. It was anticipated that sometime during a two-hour period each selected teacher would find it convenient to rate the scales for about fifteen minutes. The ten buildings were visited between April 1st and 15th, 1982. 
Upon arrival at each building the investigator checked in at the office, introduced herself to the principal and requested the scheduled breaks of each teacher who was to participate. At the break time for each teacher the investigator sought that person and made arrangements to administer the scales. The scales were either administered in the teacher's vacated classroom, the library, the faculty lounge, or the office of the principal. The most quiet, uninterrupted area was selected.

The investigator made the participants as comfortable as possible. Coffee or tea was available. After orally directing the participants as to responses on the scale, the investigator remained close at hand, yet unobrusive, to answer any questions the participants might have had. Because Friday can be a disruptive day, only Monday, Tuesday, Wednesday, and Thursday were selected to visit schools.

This procedure just described continued nine additional times in nine other buildings.

For control purposes, the scale was administered as closely together as possible and as many were completed as possible before the first workshop, which was given on April 9,1982 . 
Design and Implementation of Active Involvement Workshops

For the active involvement workshops the investigator developed a schedule to be followed at each presentation (Table $\mathrm{X}$ ). The activities of each active involvement workshop are described in the following sections.

TABLE X

TIME SCHEDULE OF ACTIVE INVOLVEMENT WORKSHOP

\begin{tabular}{lrc}
\hline Activity & Morning Workshops & Afternoon Workshops \\
\hline & $9: 45-10: 00$ & $3: 00-3: 15$ \\
Arrival & $10: 00-10: 07$ & $3: 15-3: 22$ \\
Orientation & $10: 07-10: 15$ & $3: 22-3: 30$ \\
Video Tape & $10: 15-10: 30$ & $3: 30-3: 45$ \\
Sound/filmstrip & $10: 30-10: 35$ & $3: 45-3: 50$ \\
Videotape & $10: 35-10: 50$ & $3: 50-4: 05$ \\
Role-playing \& & Simulation & $4: 05-4: 15$ \\
Administration of & $10: 50-11: 00$ & \\
\hline
\end{tabular}

Arrival. As participants arrived, the investigator had completely arranged the room and equipment to be used. The sessions were held after school in a quiet, uninterrupted area in the library, except for the first workshop which was held in the administration building in the mid-morning, 10-11 o'clock, a.m. Participants sat in small groups at two or three round tables depending on the total group size (Table XI). Coffee, tea, and cookies were available. Each participant was greeted by the investigator, thanked for coming, and attendance recorded. 
TABLE XI

ACTIVE INVOLVEMENT GROUPS

\begin{tabular}{|c|c|c|c|c|}
\hline Workshop Location & Date & Time & $\begin{array}{l}\text { Group } \\
\text { Size }\end{array}$ & Table \\
\hline $\begin{array}{l}\text { Administration } \\
\text { Building }\end{array}$ & $4 / 9$ & $10-11$ am & 8 & 1 rectangle \\
\hline Montclair School & $4 / 20$ & $\begin{array}{l}3: 15- \\
4: 15 \mathrm{pm}\end{array}$ & 10 & 2 round \\
\hline Aloha Park School & $4 / 29$ & $\begin{array}{l}3: 15- \\
4: 15 \mathrm{pm}\end{array}$ & 11 & 2 round \\
\hline
\end{tabular}

Orientation. Terminology was defined with the use of some visuals. Hearing-impaired was orally defined as any loss of hearing (mild-moderate-severe-profound.) Decibel was defined as a unit of loudness. Middle-ear loss was described as a loss in loudness of sound and was visually shown on a poster as written in very tiny letters so no participants could see it (Appendix N). Inner-ear loss was defined as the loss in ability to distinguish between the various sounds in our language (Appendix N). This usually represents a loss in clarity. Based on an article by Davis et al. (1981) the investigator presented a synopsis of the estimated numbers of children with hearing losses who are in regular classrooms and the difficulties regular classroom teachers face in educating these children. 
A short audio tape was presented which simulated middle-ear hearing losses (loudness loss) at 10 decibel intervals and inner-ear hearing losses at various pitch ranges (or loss of clarity). The tape causes the audience to bend forward and listen very carefully. The feeling of a hearing loss is well presented. The tape consisted of segments from "How They Hear" by Harford (1969). Seven minutes were scheduled for this activity.

Participants were encouraged to ask questions. Videotape recording and discussion. To introduce to teachers the type of background a hearing-impaired child encounters, a videotape recording was presented. The videotape titled "Jacque's Story" follows Jacque from age 13 months, when her profound hearing loss was diagnosed, to age seven when she enters public school regular classrooms. The tape shows Jacque at about 6-9 month intervals. The progress she begins to make once she is aided (given hearing aids) is quite astounding and obvious. Her speech development is reflected in babbling, single words and jargon, phrases and finally sentences. The tape summarizes by discussing the fact that Jacque is one of the lucky children who was diagnosed and helped. Also, through special training and acceptance, she is not embarrassed by her handicap nor afraid to ask questions when something is unclear to her. It is this pre-school training that allows her successfully to mainstream into the regular classroom. 
Her success in the regular clasroom depends on teacher and peer acceptance and understanding of her and her handicap. Jacque is a beautiful, little girl who is precocious, enthusiastic and loveable. Those who view this tape tend to love everything about her. The tape "hooks" its audience and causes viewers to realize she is a little girl like all little girls.

"Jacque's Story" was produced by Good Samaritan Hospital, Portland, Oregon, in conjunction with Infant Hearing Resource (IHR). This is a non-profit group whose purpose is to educate families and their hearing-impaired child, age birth to four-years-old.

Participants responded warmly to the tape and the investigator encouraged discussion from the participants. The most difficult problem was graciously ending discussion. Eight minutes were scheduled for this activity. Sound/filmstrip and discussion. An audio-cassette and filmstrip were introduced by suggesting that as they view and listen to the presentation, they think about their teaching, their classrooms, materials, and resources as compared to the sound/filmstrip. It was pointed out that much of what they already do is appropriate for normal hearing children as well as those who are hearing-impaired. Any adaptations required for the hearing-impaired are usually fairly simple and more than likely encourage as much or more learning from the normal-hearing child, such as the 
use of visuals or summarizing important points of class discussion for those who had difficulty following the conversation.

The sound/filmstrip titled "Classroom Communications" was selected from the Systems O.N.E. materials developed by Bitter and Johnson (1974b). This sound/filmstrip presents techniques for lesson presentation, modifications of the physical classroom arrangement, modification for speechreading conditions, and incorporation of auditory training into regular classroom activities.

Discussion followed, fielded by questions from the investigator. The questions for discussion were written by Bitter and Johnson (1974b) and were included in the sound/filmstrip guide. Fifteen minutes were scheduled for this activity.

Videotape recording of reading lips. A short videotape recording was presented of a young man holding up basic items such as a pencil, fork, doll, and so forth (nine items total) and without sound mouthed the word in Spanish. The participants were given paper and pencil to write down what they felt they had read (Iip reading or speech reading). The correct answers were then given auditorally. The use of Spanish made the lip reading as difficult for the teachers as what English might be for the hearing-impaired child to interpret. Five minutes were scheduled for this activity. Role-playing and simulation. A brief oral presentation, 
accompanied with a visual chart (Appendix $\mathrm{N}$ ), was given regarding the common problems encountered with hearing aids and the uses of non-verbal communication. It was mentioned that both of these would be role-played or simulated and referral to the chart might be helpful.

The participants in dyads, and possibly one triad, if the total group number was odd, were given hearing aids, ear molds, and a simple stethoscope to experience listening through a hearing aid as their partners spoke to them. Also, they were given role-playing situations for practicing non-verbal communication (Appendix $N$ ). The situations were printed on cards and distributed randomly. The situations to role-play were typical of what a hearing-impaired child might need to state in the classroom but whose language is unintelligible. The investigator circulated among the groups answering questions from the participants. Fifteen minutes were scheduled for this activity. Administration of scale. The investigator presented oral directions for the scale and was available to answer questions. It was believed that this activity would take between ten and fifteen minutes. Fifteen minutes were scheduled for this activity. 


\section{Design and Implementation of Passive}

Involvement Workshops

For the passive involvement workshops the investi-

gator developed a schedule to be followed at each

presentation (Table XII).

TABLE XII

TIME SCHEDULE OF PASSIVE INVOLVEMENT WORKSHOPS

\begin{tabular}{ll}
\hline Activity & Time Schedule \\
\hline Arrival & $3: 00-3: 15$ \\
Orientation & $3: 15-3: 19$ \\
Videotape & $3: 19-3: 24$ \\
Sound/filmstrip & $3: 24-3: 35$ \\
Videotape & $3: 35-3: 39$ \\
Sound, filmstrip & $3: 39-3: 49$ \\
Demonstration & $3: 49-4: 04$ \\
Scale Administration & $4: 04-4: 15$ \\
Discussion and Hands-on & after $4: 15$ \\
\hline
\end{tabular}

Arrival. The same procedures were followed as for the active involvement workshop except that group size changed (Table XIII).

TABLE XIII

PASSIVE INVOLVEMENT GROUPS

\begin{tabular}{lcccc}
\hline Workshop Location & Date & Time & $\begin{array}{l}\text { Group } \\
\text { Size }\end{array}$ & Tables \\
\hline Montclair School & $4 / 19$ & $\begin{array}{r}3: 15- \\
4: 15\end{array}$ & 14 & 2 round \\
Aloha Park School & $4 / 28$ & $\begin{array}{r}3: 15- \\
4: 15\end{array}$ & 13 & 2 round \\
\hline
\end{tabular}


The same general procedures were followed in the passive involvement workshops as for the active involvement workshops except that participants who wanted to discuss points were asked to wait until later. The investigator planned for discussion after the attitude scales were administered. The following changes were made for the passive involvement group presentations.

An audio-cassette and filmstrip was introduced to the passive involvement groups to suggest the importance of knowledge regarding hearing aids and how they work. The sound/filmstrip titled "Hearing Aids" was selected from the Systems O.N.E. materials developed by Bitter and Johnson (1974b). This presentation includes kinds of aids, components of aids, possible malfunctions, and classroom modifications needed for an aided child. An explanation of the component parts of a hearing aid was given as the investigator demonstrated each area on an aid. The term feedback was explained (Appendix N). The investigator demonstrated the non-verbal situations for the participants who tried to interpret them but without discussion. After the scales were administered the investigator answered questions and made hearing aids available to manipulate.

\section{Summary of two types of workshops}

Except for the first workshop, an active and passive workshop was given each week in each of the two buildings. 
This was done for several reasons. This spread the workshops evenly over time and alternated the two types. This prevented the presenter from becoming better skilled at delivering one or the other. If teachers discussed the workshops in their buildings with teachers who were yet to participate, a contamination was introduced to both workshops, presumably equal.

The workshops were scheduled two consecutive days in one building for ease of delivery and set up of equipment. Prior to each of the five sessions, reminder notes were sent to each participant (Appendix 0). All participants who volunteered did attend and all participated fully. At every workshop, one or more participants remained afterward with further questions or comments. All who participated appeared enthusiastic and interested in the topic.

\section{Statistical Design}

The investigator selected a univariate, one-way analysis of variance design with the alpha level set at .05 . One of the criterion tests for measuring the influence of the independent variable on teacher attitudes toward the hearing-impaired was the Attitudes to Deafness Scale (Cowen et al., 1967). A second criterion test used to measure the influence of the independent variable on teacher attitudes toward the hearing-impaired was the Teacher scale of 
Attitudes Toward the Hearing-Impaired Student developed for this study. The power of the statistical test (Cohen, 1971) of the analyses of variance was computed to determine the effectiveness of the statistical design. The investigator expected that the group mean of the active participation group attitudes would be more positive than either the group mean of the passive participation group or the group mean of the control group for each of the two tests. The following hypotheses were tested, using a univariate one-way analysis variance for each of the criterion tests.

\section{Hypotheses}

$H_{O}$. The statistical hypothesis was that the three subpopulation means of the scores of teachers on the Attitudes to Deafness Scale will be equal and the subpopulation means of the scores of teachers on the Teacher scale of Attitudes Toward the Hearing-Impaired student will be equal. ( $\mathrm{H}_{\mathrm{O}}: \mu_{\mathrm{A}}=\mu_{\mathrm{P}}=\mu_{\mathrm{C}}$, where "A" is the active involvement workshop, "P" is the passive involvement workshop, and "C" is the no workshop control.)

$\mathrm{H}_{1}$. The research hypothesis was that not all subpopulation means of the scores of the teachers on the Attitudes to Deafness Scale will be equal and not all subpopulation means of the scores of teachers on the Teacher scale of 
Attitudes Toward the Hearing-Impaired Student will be equal. ( $\mathrm{H}_{1}$ : not all 's are equal.)

In the event that the statistical hypothesis for the univariate, one-way analysis of variance on a criterion test was rejected, the Scheffé test was to be applied to the three mean combinations for that criterion test: active participation group (A) with passive participation group (P), active participation group with the control group (C), and passive participation group with the control group. Therefore, for each comparison the following hypotheses were to be tested:

$$
\begin{aligned}
& \mathrm{H}_{0}: \mu_{1}=\mu_{2} \\
& \mathrm{H}_{1}: \mu_{1}>\mu_{2} \\
& \mathrm{H}_{2}: \mu_{1}<\mu_{2}
\end{aligned}
$$


CHAPTER IV

\section{PRESENTATION OF THE DATA}

\section{Introduction}

The purpose of this study was to determine if teacher attitudes toward the hearing-impaired can be positively modified by using two contrasting types of workshops. The random sample, selected from a suburban school district in a Northwest metropolitan area, consisted of 86 regular classroom elementary teachers. The sample was divided into three groups. The control group consisted of 30 teachers. The active involvement treatment group had 29 participants and the passive involvement treatment group had 27 participants. Following the treatment workshops the teachers were given two tests to measure attitudes. The control group was also given these tests. The data collected are presented in this chapter beginning with a discussion of the reliability and intercorrelations for each test. Next, descriptive statistics for the tests are presented. Lastly, data from a one-way anzlysis of variance and a power analysis of the statistical test for each of the two criterion tests are presented. 


\section{Reliabiity and Intercorrelations of the Tests}

As discussed in Chapter II of this investigation, Cowen, Bobgrove, Rockway, and Stevenson (1967) presented a reliability score of .83 for the Attitudes to Deafness Scale. The investigator presented a reliability score of .85 for the Teacher Scale of Attitudes Toward the Hearing-Impaired student. Both of these scales were subsequently administered to the participants in this study as a part of the data collection process.

More germane to the investigation at hand is the reliability of the instruments with the sample used in this study. Table XIV reflects the coefficients of reliability and intercorrelation for each test by individual groups and by the total sample of each test. The reliability coefficients for the study sample using the Attitudes to Deafness Scale (Cowen et al., 1967) were .93 for the control group, .94 for the active participation group, and .73 for the passive group. The overall reliability score for the test was .91 . The reliability coefficients for the study sample using the Teacher scale of Attitudes Toward the Hearing-Impaired student developed by the investigator were .92 for the control group, .94 for the active group and .94 for the passive group. The overall reliability score for test was .94. The data collected for the study sample were submitted to the SPSS Subprogram, RELIABILITY. The model was ALPHA (Hull \& Nie, 1981). 
Using SPSS Subprogram, PEARSON CORRELATION, model ALPHA (Hull \& Nie, 1981), the coefficients of correlation between the tests were calculated separately for each group and for all groups combined. The intercorrelation coefficients of the tests were $\underline{r}=.6761$ for the control group, $\underline{\underline{r}}=.8525$ for the active participation group, and $\underline{\underline{r}}=$ .0367 for the passive participation group. The intercorrelation on all groups together was $\underline{r}=.5329$.

TABLE XIV

COEFFICIENTS OF RELIABILITY AND INTFRCORREI.ATION FOP EACH TEST BY INDIVIDUAL GROUPS AND TOTAL SAMPLE

\begin{tabular}{lllll}
\hline $\begin{array}{l}\text { Characterists } \\
\text { of the tests }\end{array}$ & $\begin{array}{l}\text { Control } \\
\text { Group }\end{array}$ & $\begin{array}{l}\text { Active } \\
\text { Partici- } \\
\text { pation }\end{array}$ & $\begin{array}{l}\text { Passive } \\
\text { Partici- } \\
\text { pation }\end{array}$ & Total \\
\hline $\begin{array}{l}\text { Cowen et al. } \\
\text { reliability }\end{array}$ & .9299 & .9377 & .7338 & .9103 \\
$\begin{array}{l}\text { Mcclain reliability } \\
\begin{array}{l}\text { Correlations between } \\
\text { the tests }\end{array}\end{array}$ & .9229 & .9401 & .9449 & .9379 \\
\hline
\end{tabular}

\section{Descriptive Statistics for the Tests}

The SPSS Subprogram, SCORE FREQUENCIES (Hull \& Nie, 1981 ) and SPSS subprogram, ONEWAY (Nie et al., 1975) were used to construct frequency distributions and to compute the means and standard deviations of the data collected $(\underline{N}=86)$ for the two attitude scales administered for this investigation. A low score on either test indicated a positive 
attitude. The higher the score on either test, the more negative was the respondent's attitude. With 25 items and a maximum of four points per item, the range of scores was 25-100. For the Attitudes to Deafness Scale (Cowen et al., 1967), means and standard deviations were computed for the control group $(\underline{\bar{x}}=44.43, \underline{S D}=8.9)$, the active participation group $(\underline{\bar{x}}=42.21, \underline{S D}=10.0)$, and the passive particiation group $(\underline{\bar{x}}=47.67, \underline{S D}=5.6)$. For the total sample the grand mean for this test was 44.70 and the overall standard deviation 8.7. For the Teacher scale of Attitudes Toward the Hearing-Impaired student developed by the investigator, means and standard deviations were computed for the control group $(\underline{\bar{x}}=47.80, \underline{S D}=8.5)$, the active participation group $(\underline{\bar{X}}=44.59, \underline{S D}=10.0)$, and the passive participation group $(\underline{\bar{X}}=42.89, \underline{S D}=10.1)$. For the total sample the grand mean for this test was 45.17 and the overall standard deviation was 9.7. See Tables XIV, XV, XVI, XVII, and XVIII. 
TABLE XV

ATTITUDES TO DEAFNESS SCALE FREQUENCY

DISTRIBUTION OF ATTITUDE SCORES

BY GROUP AND TOTAL SCORES

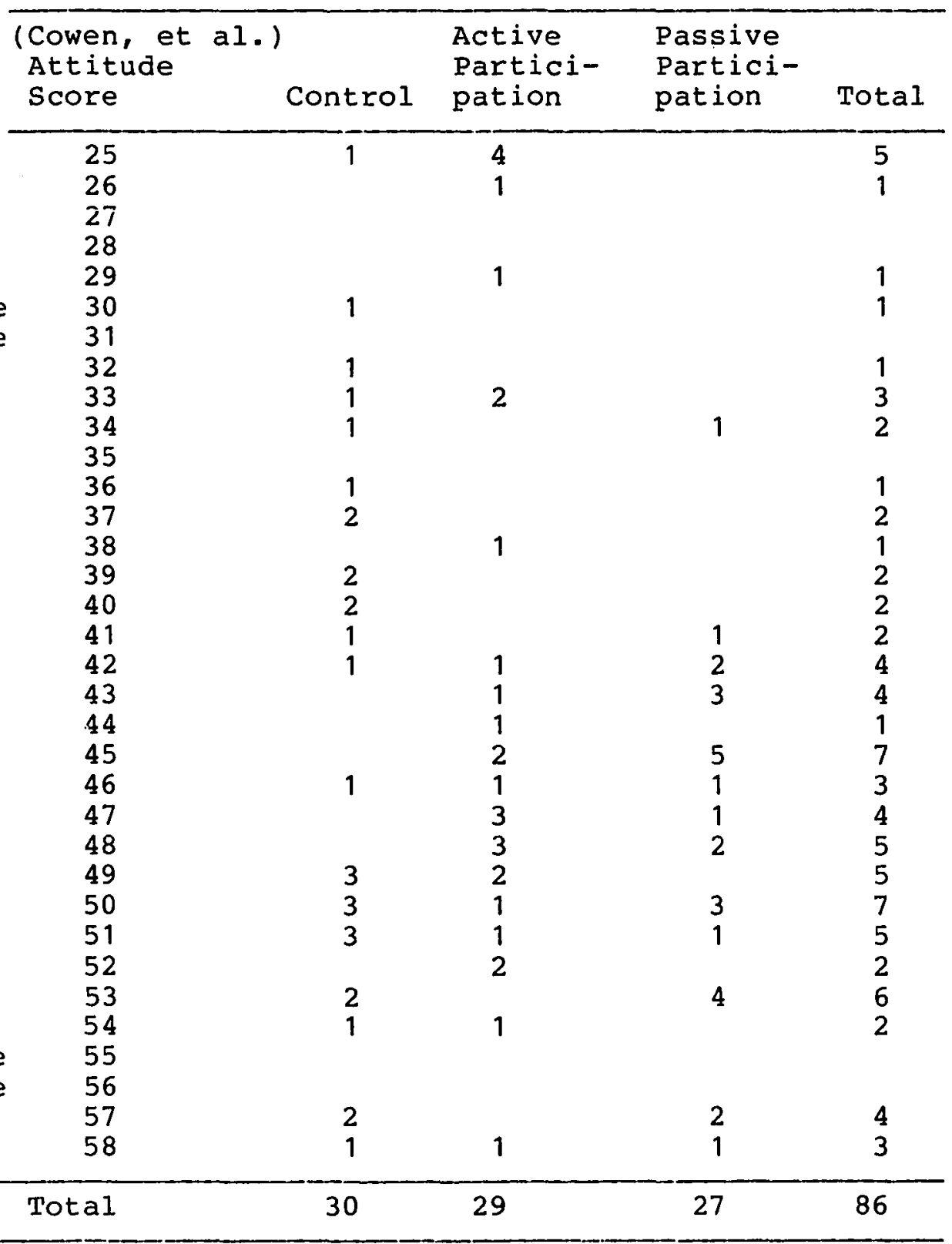


TABLE XVI TEACHER SCALE OF ATTITUDES TOWARD THE HEARING-
IMPAIRED STUDENT FREQUENCY DISTRIBUTION OF
ATTITUDE SCORES BY GROUP AND TOTAL SCORES

\begin{tabular}{|c|c|c|c|c|}
\hline $\begin{array}{l}\text { (McClain) } \\
\text { Attitude } \\
\text { Score }\end{array}$ & Control & $\begin{array}{l}\text { Active } \\
\text { Partici- } \\
\text { pation }\end{array}$ & $\begin{array}{l}\text { Passive } \\
\text { Partici- } \\
\text { pation }\end{array}$ & Total \\
\hline $\begin{array}{l}25 \\
26 \\
27 \\
28 \\
29 \\
30 \\
31 \\
32 \\
33 \\
34 \\
35 \\
36 \\
37 \\
38 \\
39 \\
40 \\
41 \\
42 \\
43 \\
44 \\
45 \\
46 \\
47 \\
48 \\
49 \\
50 \\
51 \\
52 \\
53 \\
54 \\
55 \\
56 \\
57 \\
58 \\
59 \\
60 \\
61\end{array}$ & $\begin{array}{l}3 \\
2 \\
\\
1 \\
1 \\
1 \\
1 \\
2 \\
3 \\
2 \\
2 \\
2 \\
1 \\
1 \\
1 \\
1 \\
1 \\
2 \\
1\end{array}$ & $\begin{array}{l}1 \\
1 \\
1 \\
1 \\
1 \\
1 \\
2 \\
1 \\
1 \\
3 \\
1 \\
2 \\
1 \\
2 \\
1 \\
1 \\
1 \\
1 \\
1\end{array}$ & $\begin{array}{l}1 \\
2 \\
1 \\
1 \\
1 \\
3 \\
2 \\
1 \\
2 \\
2\end{array}$ & $\begin{array}{l}2 \\
1 \\
1 \\
1 \\
1 \\
1 \\
1 \\
3 \\
1 \\
\\
1 \\
4 \\
2 \\
1 \\
2 \\
3 \\
1 \\
3 \\
3 \\
3 \\
5 \\
5 \\
7 \\
5 \\
6 \\
3 \\
3 \\
1 \\
1 \\
2 \\
2 \\
3 \\
2\end{array}$ \\
\hline Total & 30 & 29 & 27 & 86 \\
\hline
\end{tabular}


TABLE XVII

SUMMARY STATISTICS FOR THE ATTITUDES TO DEAFNESS SCALE BY GROUP

\begin{tabular}{llcc}
\hline Group & N & $\underline{M}$ & $\underline{\text { SD }}$ \\
\hline Control sample & 30 & 44.43 & 8.9 \\
Active participation & 29 & 42.21 & 10.0 \\
Passive participation & 27 & 47.67 & 5.6 \\
Total & 86 & 44.70 & 8.7 \\
\hline
\end{tabular}

TABLE XVIII

SUMMARY STATISTICS FOR THE TEACHER SCALE OF ATTITUDES TOWARD THE HEARING-IMPAIRED STUDENT BY GROUP

\begin{tabular}{llcc}
\hline Group & $\underline{N}$ & $\underline{M}$ & $\underline{\text { SD }}$ \\
\hline Control sample & 30 & 47.80 & 8.5 \\
Active participation & 29 & 44.59 & 10.0 \\
Passive participation & 27 & 42.89 & 10.1 \\
Total & 86 & 45.17 & 9.7 \\
\hline
\end{tabular}




\section{Attitudes to Deafness Scale}

Following the administration of the Attitudes to Deafness Scale developed by Cowen et al. (1967), the data were submitted to SPSS, subprogram, ONEWAY (Nie et al.., 1975). Alpha was set at .05. The statistical hypothesis that there would be no significant differences in attitudes of teachers among the control group, the active involvement group and the passive involvement group, as measured by the Attitudes to Deafness Scale was not rejected. Examination of Table XIX indicates that were were no significant treatment effects among the three group samples $(\underline{F}=2.93$, $\underline{p}<.06)$.

TABLE XIX

ANALYSIS OF VARIANCE SUMMARY OF STATISTICS FOR THE ATTITUDES TO DEAFNESS SCALE

\begin{tabular}{lrrrr}
\hline Source & SS & df & $\underline{\text { MS }}$ & $\underline{F}$ \\
\hline Between groups & 420.02 & 2 & 210.01 & $2.93^{*}$ \\
Within groups & 5948.13 & 83 & 71.66 & \\
Total & 6368.15 & 85 & & \\
\hline
\end{tabular}

${ }^{*} \mathrm{p}<.06$ 
To evaluate the statistical design, the power of the statistical test of the analysis of variance was computed. "The power of a statistical test is the probability that it will yield statistically significant results" (Cohen, p. 1, 1971). The power analysis for the effect size obtained by this study was .995 .

\section{Teacher Scale of Attitudes Toward the} Hearing-Impaired Student

Following the administration of the Teacher scale of Attitudes Toward the Hearing-Impaired student, developed by the investigator, the data were submitted to the SPSS subprogram, ONEWAY (Nie et al., 1975). Alpha was set at .05. The statistical hypothesis that there would be no significant differences in attitudes of teachers among the control group, the active involvement group and the passive involvement group as measured by the Teacher scale of Attitudes Toward the Hearing-Impaired student was not rejected. Examination of Table $\mathrm{XX}$ indicates that there were no significant treatment effects among the three samples (F $=1.96, \mathrm{p}(.15)$.

To evaluate the statistical design the power of the statistical test of the analysis of variance was computed. The power analysis for the effect size obtained by this study was .975 . 
TABLE XX

ANALYSIS OF VARIANCE SUMMARY OF STATISTICS FOR THE TEACHER SCALE OF ATTITUDES TOWARD THE HEARING-IMPAI RED STUDENT

\begin{tabular}{lrrrr}
\hline Source & SS & df & $\underline{\text { MS }}$ & $\underline{E}$ \\
\hline Between groups & 357.88 & 2 & 178.94 & $1.96 *$ \\
Within groups & 7570.50 & 83 & 91.21 & \\
Total & & 85 & & \\
\hline
\end{tabular}

${ }^{*} \mathrm{p}<.15$ 


\section{CHAPTER V}

\section{CONCLUSIONS AND IMPLICATIONS}

\section{Introduction}

The study was designed to determine if teacher attitudes toward the hearing-impaired can be positively modified by using two contrasting types of workshops. Instruments and procedures were developed to test whether the treatment workshops made a difference in modifying teachers' attitudes. The remainder of this chapter deals with the conclusions and implications of the study.

\section{Conclusions}

Analysis of the data from this study yielded the following information.

1. Coefficients of reliability were computed for the instruments used with the sample for this study. The combined samples coefficient of reliability (Alpha) for the Attitudes to Deafness Scale was .91 and for the Teacher Scale of Attitudes Toward the Hearing-Impaired Student was .94.

2. For the combined samples, the Pearson product moment coefficient of correlation was . 53 . 
3. A one-way analysis of variance was performed on the Attitudes to Deafness Scale. The calculated E of 2.93 was not significant at the .05 level of confidence; the statistical hypothesis was not rejected. A power of the statistical test for the effect size obtained in this analysis was .995 .

4. A one-way analysis of variance was performed on the Teacher scale of Attitudes Toward the Hearing-Impaired student. The calculated $\underline{F}$ of 1.96, was not significant at the .05 level of confidence; the statistical hypothesis was not rejected. A power of the statistical test for the effect size obtained in this analysis was .975 . The reliability coefficients obtained on the instruments used in this study indicated that the instruments possess internal consistency; the instruments apparently provided adequate control of internal errors of measurement. The coefficient of correlation between the two tests was moderate $(\underline{\underline{r}}=+.53)$. It is reasonable to conclude that the two tests were measuring related but not identical attitudes. The investigator initially determined that the test by Cowen et al. (1967) was not entirely suitable for testing attitudes toward children and subsequently developed the attitude scale aimed specifically toward hearing-impaired students. Although the analysis of variance for each test yielded no significant differences, 
the power of the statistical tests indicated that the tests were powerful enough to find differences in attitude shifts. The survey of literature caused the investigator to expect large attitude shifts. Thus, the group sample size seemed to be acceptable. Consequently, it is reasonable to conclude that treatment workshops of the duration of one hour in length are not likely to produce attitude shifts of acceptable magnitude. The survey of Iiterature in Chapter II of this investigation supports this conclusion (Haring et al., 1958; Blake, 1971; Joyce et al., 1977; Wilson \& Alcorn, 1969; and Seltz, 1973). Given the power of the statistical tests, the attitude scales might have yielded larger differences had the workshops been longer in duration.

In comparing the sample mean (51.02) in the Cowen et al. (1967) study using the Attitude to Deafness Scale with the mean (44.43) of the control group in this investigation on the same test one can observe that there was less opportunity for change of attitudes to occur in this study. On the scale of $25-100,25$ the most positive score, the range of potential movement in this study was restricted. The control group attitudes possessed $85 \%$ of the possible positive range points. Due to the random selection of the sample, one can assume that the two treatment groups were similar in attitudes to the control group at the beginning of this study. It therefore seems reasonable to suspect 
that the treatment groups may have met part of the expected outcomes prior to the workshop treatinents. Thus, significant differences would be difficult to detect. The initial positive attitudes of the sample in this study could be related to the fact that they had been exposed to a variety of mainstreamed children in their buildings which affected their attitudes and sensitivity.

The participants were all volunteers. The fact that they volunteered may indicate an existing sensitivity to the handicapped. The volunteer process may have culled out those who might have made significant attitude shifts. One must question the use of volunteer samples when measuring attitudes.

These conclusions are subject to the conditions and limitations of this study as discussed in Chapter III. Specifically, one should consider that the instrument selection was limited due to the few in existence appropriate to this study. Further, the study sample was limited to suburban elementary classroom teachers from a Northwest metropolitan area.

\section{Implications}

The significance of this study depends on the application of the results to the development of in-service training programs for teachers. School districts of the nature used for the sampling in this study, who wish to make more 
positive teachers' attitudes toward hearing-impaired students, need to consider the duration of time allowed for in-service programs. One-hour sessions after a day of teaching do not appear effective. An examination of the Iiterature and the findings in this investigation suggest that teachers should be given release time in keeping with the Seltz (1973) model of at least two and one-half hours in length. (The investigator's experience in attempting to get teachers to volunteer to participate in this study resulted in the fact that they would only volunteer to attend workshops for one hour after school).

Although there were no significant differences among the group means and overall mean for each criterion test administered, examination of the summary statistics (see Tables XVII and XVIII) indicates some shifts of attitude occurred. On the Teacher scale of Attitudes Toward the Hearing-Impaired student the active involvement group and the passive involvement group both resulted in positive shifts of attitudes. On the Attitude to Deafness Scale the active involvement group resulted in a positive attitude shift, but the passive involvement group indicated a negative shift of attitudes. One might speculate that the workshops may have had greater impact in modifying attitudes toward hearing-impaired children in particular than toward the hearing-impaired in general. Further research is needed to verify such a speculation. 
The 1 iterature also indicated that active involvement should make a difference in modifying attitudes. Assuming teachers are already sensitive people, the added value of this format is in question. As a result of this study, a school district inight question the need of in-service education for the purpose of modifying attitudes toward the hearing-impaired if such children are already mainstreamed into the regular classrooms. A school district might consider pre-testing teachers to assess specific in-service needs. This would enable administrators to determine individual attitudes of teachers and possibly to require in-service for those teachers whose pre-test scores indicate negative attitudes. Pre-testing would further help administrators determine if such in-service is even necessary. It might be reasonable to ask whether one-hour workshops might disrupt existing attitudes, where longer, in-depth, workshops might encourage the development of new attitudes. Little is known about how much time is needed to change attitudes. According to Wilson and Alcorn (1969) to modify teachers' attitudes to become more positive toward the hearing-impaired, objectives need to be designed to go beyond discupting existing attitudes to formulating new ones.

In this investigation, the literature has consistently pointed out that as a whole, regular classroom teachers are not prepared with positive attitudes to teach hearing- 
impaired children effectively. The results of this investigation do not validate the efficacy of treatment workshops to improve teachers' attitudes toward the hearing-impaired. However, the results do imply that research is needed to establish the relationship between effective in-service training and effective positive attitude development. 


\section{REFERENCE NOTES}

1. Dr. H. William Brelje. Professor and Director, Programs in Special Education--Hearing-Impaired, Lewis and Clark College, Portland, Oregon.

2. Dr. Carolyn Bullard. Associate Professor, Programs in Special Education--Hearing-Impaired, Lewis and Clark College, Portland, Oregon. 
BIBLIOGRAPHY

Alexander, C., \& Strain, P. S. A review of educators' at-titudes toward handicapped children and the concept of mainstreaming. Psychology in the Schools, 1978, 15, 390-396.

Allen, Dwight $w$. In-service teacher training. In Louis J. Rubin (Ed.), Improving in-service education: Proposals and procedures for change. Boston: Allyn \& Bacon, 1971 .

Anderson, C. L. School health practices. St. Louis: $V$. Mosby, 1968.

Bents, Richard H., \& Howey, K. R. Staff development change in the individual. In Betty Dillon-Peterson (Ed.), Staff development/organization development. Alexandria, Va.: ASCD, 1981.

Bitter, G. B., \& Johnson, K. A. Facilitating the integration of hearing impaired children into regular public school class: Final report. Washington, D.C.; Bureau for the Handicapped, 1974. (ERIC Document Reproduction Service No. ED 143161 ) (a)

Bitter, G. B., \& Johnson, K. A. Systems O.N.E. Kit. Salt Lake City: Audio Reprint, 1974. (sound filmstrip) (b)

Blake, G. D. An experiment in serving deaf adults in a comprehensive rehabilitation center. Little Rock: Rehabilitation Service, 1970.

Blake, G. D. Effects of integrated training experience on the attitudes of hearing adults toward deaf adults and deafness (Doctoral dissertation, University of Arkansas, 1971). Dissertation Abstracts International, $1971,318 \overline{09-A-810-A . ~(U n i v e r s i t y ~ M i c r o f i l m s ~}$ No. $71-20,717 \overline{1}$

Bobgrove, P. H. Adjustment to auditory disability in adolescence, Unpublished doctoral dissertation, University of Rochester, 1965. 
Bourdeau, Lise, \& Ryan, Thomas. Teacher interaction with preschool children: Attitudes, contacts, and their effects. Canadian Journal of Behavioral Sciences, $1978,10,283-285$.

Brimm, J. L. \& Tollett, D. J. How do teachers feel about in-service education? Educational Leadership, 1974, 31, 521-524.

Brophy, J., \& Good, T. Teacher-student relationships. New York: Holt, Rinehart \& Winston, 1974.

Cantrell, R. P., \& Cantrell, M. L. Preventive mainstreaming: Impact of a supportive services program on pupils. Exceptional Children, 1976, 42, $381-386$.

Chickering, A. W. Developmental change as a major outcome. In M. T. Keeton \& Associates (Eds.), Experiential learning: Rationale, characteristics, and assessment. San Francisco: Jossey-Bass, 1976.

Clore, G. L., \& Jeffery, K. M. Emotional role playing, attitude change, and social attraction toward a disabled person. Journal of Personality and Social Psychology, 172, 23, 105-111.

Cohen, Jacob. Statistical power analysis for the behavioral sciences (2nd ed.). New York: Academic Press, 1971.

Coleman, J. S. Differences between experiential and classroom learning. In M. T. Keeton and Associates (Eds.), Experiential learning: Rationale, characteristics, and assessment. San Francisco: Jossey-Bass, 1976 .

Combs, R. H., \& Harper, J. L. Effects of labels on attitudes of educators toward handicapped children. Exceptional Children, 1967 33, 399-403.

Conine, T. A. Acceptance or rejection of disabled persons by teachers. Journal of School Health, 1969, 39, $278-280$.

Cowen, E. L., Bobgrove, P. H., Rockway, A. M., \& Stevenson, $\mathrm{J}$. Development and evaluation of an attitudes to deafness scale. Journal of Personality and Social Psychology, 1967, 6 183-191.

Cowen, E. L., \& Cowen, R. S. A comparison of the attitudes of American and French college students towards deafness and blindness. Paper presented at the 
meeting of the American Psychological Association, Philadelphia, August 1963.

Cowen, E. L., Underberg, R. R., \& Verrillo, R. T. The development and testing of an attitude to blindness scale. Journal of Social Psychology, 1958, 48, 297-304.

Dailey, J., \& Halpin, G. Modifying undergraduates' attitudes toward the handicapped. Journal of Special Education, $1981,15,333-339$.

Davis, J. M., Shepard, N., Stelmackowicz, P., \& Gorga, M. Perceptions of hearing impairment held by school personnel: Suggestions for in-service training and development. Language, Speech and Hearing Services in Schools, 1981, I, 168-177.

Deleo, A. The attitudes of public administrators and teachers toward the integration of children with specific needs into regular education programs (Doctoral dissertation, Boston College, 1976). Dissertation Abstracts International, 1976, 37, 915-A916-A. (University Microfilms No. 76-18, 930)

DeVault, M. V., Houston, W. R., \& Boyd, Charles. Report of research (Office of Education). Washington, D.C.: U. S. Government Printing Office, 1962. (Mimeographed paper)

Dietrich, David C. Review of research. In Richard Hill (Ed.), A comparative study of lecture and discussion methods. New York: Fund for Adult Education, 1960 .

Donaldson, J., \& Martinson, M.C. Modifying attitudes toward physically disabled persons. Exceptional Children, $1977, \underline{43}, 337-341$.

Duke, Daniel L. Leadership functions and instructional effectiveness. Unpublished manuscript, 1982. (Available from Lewis and Clark College, Portland, OR.).

Duker, Sam. Listening and reading. Elementary School Journal, $1965, \underline{65}, 321-329$.

Dunn, R. S., \& Dunn, K. J. Learning styles/teaching styles. Educational Leadership, 1979, 36, 238-244.

Emerton, R. G., \& Rothman, G. Attitudes towards deafness: Hearing students at a hearing and deaf college. American Annals of the Deaf, $1978, \underline{123}, 588-593$. 
Ernst, William. What makes a workshop jell? Educational Leadership, $1974,31,496-498$.

Ferguson, L. '?. Components of attitudes toward the deaf. Proceedings of the 78th Annual Convention of the American Psychological Association, 1970, 5. 693-694.

Germain, Lois Bell. Inservice training: Mini-model. In Winifred Northcott (Ed.), The hearing impaired child in a regular classroom: preschool, elementary and secondary years. Washington, D.C.: Alexander Graham Bell Association for the Deaf, 1973.

Gilchrist, Robert S., Fielstra, Clarence, \& Davis, A. Organization of programs of in-service education. In Nelson B. Henry (Ed.), In-service education of teachers, supervisors, and administrators. Chicago: University of Chicago Press, 1957.

Gillung, T. B., \& Rucker, C. N. Labels and teacher expectations. Exceptional Children, 1977, 43, $464-465$.

Glass, R. M., \& Meckler, R. S., Preparing, elementary teachers to instruct mildly handicapped children in regular classrooms: A summer workshop. Exceptional Children, 1972, 39, 152-156.

Good, T. L., \& Brophy, J. E. Behavioral expression of teacher attitudes. Journal of Educational Psychology, $1972,63,617-624$.

Good, T. L., \& Brophy, J. E. Looking in classrooms. New York: Harper \& Row, 1973.

Graham, G. Sociodrama as a teaching technique. Social Studies, 1960, 51, 257-259.

Graham, S., Hudson, F., Burdg, N., \& Carpenter, D. Educational personnel's perceptions of mainstreaming and resource room effectiveness. Psychology in the Schools, $1980,17,128-134$.

Greenum, R. M. Society's attitudes and popular conceptions concerning the deaf. American Annals of the Deaf, $1958,103,372-377$.

Harasymiw, S. \& Horne, M. Integration of handicapped children: Its effects on teacher attitudes. Education, 1975, 95, 153-158. 
Harasymiw, S., \& Horne, M. Teacher attitudes toward handicapped children in regular classroom integration. Journal of Special Education, 1976,10 , $393-400$.

Harasymiw, S., Horne, M., \& Lewis, S. C. Disability social distance hierarchy for population subgroups. Scandinavian Journal of Rehabilitation Medicine, 1976 , 8, 33-36.

Harford, Earl R. (Producer). How they hear. USA: Gordon Stowe \& Associates, 1964. (audio-tape)

Haring, N. G. A study of attitudes of classroom teachers toward exceptional children (Doctoral dissertation, Syracuse University, 1956). Dissertation Abstracts International, 1957, 17, 103-104. (University Microfilmes No. 19, 378)

Haring, N. G. Attitudes of educators toward exceptional children. Englewood Cliffs, N.J.: Prentice-Hall, T969.

Haring, N. G., Stern, G. S., \& Cruickshank, W. M. Attitudes of educators toward exceptional children. Syracuse, N.Y.: Syracuse University Press, 1958.

Harris, Ben. Supervisory behavior in education. Englewood Cliffs, N.J.: Prentice-Hall, 1963.

Harris, Ben. Improving staff performance through in-service education. Boston: Allyn \& Bacon, 1980.

Harris, Ben, \& Bessent, Wailand. In-service education: A guide to better practice. Englewood Cliffs, N.J.: Prentice-Hall, 1969.

Hermanowicz, Henry J. The pluralistic world of beginning teachers. In The world of beginning teachers. Washington, D.C.: National commission of Teacher Education, NEA, 1966.

Hill, Richard. A comparative study of lecture and discussion methods. New York: Fund for Adult Education, 1960 .

Horne, Marcia. Attitudes and mainstreamng: A literature review for school psychologists. Psycholgy in the Schools, 1979, 16, 61-67.

Horowitz, L. S., \& Rees, S. Attitudes and information about deafness. Volta Review, 1962, 64, 180-189. 
Hudson, Floyd, Graham, Steve, \& Warner, Michael. Mainstreaming: An examination of the attitudes and needs of regular classroom teachers. Learning Disability Quarterly, 1979, $2,58-62$.

Hul1, C. Hadlai, \& Nie, Norman (Eds.). SPSS Update 7-9: New procedures and facilities for releases 7-9. San Francisco: McGraw Hill, 1981.

Hunt, D. E. Person-environment interaction: A challenge found wanting before it was tried. Review of Educational Research, 1975, 45, 209-230.

Hunter, M. The learning process. In E. Seifman \& D. Allen (Eds.), Handbook for teachers. Glenview, Ill.: Scott-Foreman, 1971 .

I/D/E/A. Learning in the small group. Melbourne, Fla.: Institute for Development of Educational Activities, 1971.

Jackson, P. \& Lahaderne, H. Inequalities of teacher-pupil contacts. Psychology in the Schools, 1967, 4, 204-208.

Jaffe, J. Attitudes of adolescents toward mentally retarded. American Journal of Mental Deficiency, 1966, 70, 907-917.

Jaffe, J. What's in a name--attitudes towrd disabled persons. Personnel and Guidance Journal, 1967, 45, 557-560.

Janis, I. L., \& King, B. T. The influence of role playing on opinion change. Journal of Abnormal and Social Psychology, 1954, 49, 211-218.

Johnson, A. B., \& Cartwright, C. A. The roles of information and experience in improving teachers' knowledge and attitudes about mainstreaming. The Journal of Special Education, 1979, 13, 453-461.

Jordan, J. E., Morris, K. N., Mairle, J., \& Dell Orto, A. E. A Guttman facet theory paradigm for research on attitude behaviors toward disability, racial and cultural aifferences. Proceedings of the 78th Annual Convention of the American Psychological Association, 1970, $5,723-724$.

Joyce, B. R. Selecting learning experiences: Linking theory into practice. Washington, D. C.: ASCD, 1978. 
Joyce, B. R. Learning how to learn. Theory into Practice, $1980, \underline{19}, 15-27$.

Joyce, B. R., McNair, K. M., Diaz, R., McKibbin, M. D., Waterman, F. T., \& Baker, M. G. Interviews: Perceptions of Peofessionals and policy makers. In Inservice teacher education report II. Syracuse, N.Y.: National Dissemination Center, 1977.

Joyce, B., \& Peck, L. Inservice teacher education report eleven: Interviews. Syracuse, N.Y.: National Dissemination Center, 1977.

Joyce, B., \& Showers, B. Improving inservice training: The message of research. Educational Leadership, 1980, 37, 379-385.

Kelley, Earl C. The workshop way of learning. New York: Harper \& Brother, 1951.

Kraft, A. Down with (most) special education classes. Academic Therapy, 1973, 8, 207-216.

Kvaraceus, W. K. Acceptance-rejection and exceptionality. Exceptional Children, 1956, 22, 328-331.

Lapp, E. Social adjustment of slow learning children who were assigned to part-time regular classes. American

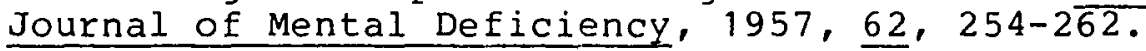

Larrivee, B. Effect of inservice training intensity on teachers' attitudes toward mainstreaming. Exceptional Children, $1981, \underline{48}, 34-39$.

Lazar, A. L., Gensley, J. T., \& Orpet, R. E. Changing attitudes of young mentally gifted children toward handicapped persons. Exceptional Children, 1971, 37, 600-602.

Levine, Jacob, \& Butler, John. Lecture versus group discussion in changing behavior. Journal of Applied Psychology, 1952, 36, 29-33.

Lippitt, Ronald, \& Fox, Robert. Effective classroom learning. In Louis J. Rubin (Ed.), Improving in-service education: Proposals and procedures for change. Boston: Allyn \& Bacon, 1971.

Loevinger, J. Ego development: Conceptions and theories. San Francisco: Jossey-Bass, 1976. 
Lowenfeld, B. Psychological problems of children with impaired vision. In W. M. Cruickshank (Ed.), Psychology of exceptional children and youth (2nd ed.). Englewood Cliffs, N.J.: Prentice-Hall, 1963.

Lynas, Wendy. The hearing-impaired child in the ordinary school. Journal of the British Association of Teachers of the Deaf, 1980, 4, 49-57.

Mandell, C., \& Strain, P. S. An analysis of factors related to the attitudes of regular classroom teachers toward mainstreaming mildly handicapped children. Contemporary Educational Psychology, 1978, 3, 154-162.

Martin, E. W. Some thoughts on mainstreaming. Exceptional Children, 1974, 41, 150-153.

McCarthy, Bernice. Improving staff development through CBAM and 4Mat. ${ }^{\mathrm{m}}$ Educational Leadership, 1980, 40, 20-25.

McKalip, Keith J. Developing acceptance toward the handicapped. The School Counselor, 1979, 26, 293-298.

McLaughlin, M., \& Marsh, D. Staff development and school change. T'eachers College Record, 1978, 80, 69-94.

Mitchell, M. Teacher attitudes. High School Journal, 1976, 59, 302-312.

Mohlman, G. G., Coladarci, T., \& Gage, N. L. Comprehension and attitude as predictors of implementation and teacher training. Journal of Teacher Education, 1982, $33,31-36$.

Murphy, A. T., Dickstein, J., \& Dripps, E. Acceptance, rejection and the hearing impaired. Volta Review, $1960, \underline{62}, 208-211$.

Nie, Norman H., Hull, C. Hadlai, Jenkins, Jean, Steinbrenner, Karin, \& Bent, Dale H. Statistical packages for the social sciences (2nd ed.). San Francisco: McGraw-Hill, 1975.

Nober, Linda $w$. An in-service program for integrating hearing impaired children. Volta Review 1975, 77, $173-175$.

Oja, Sharon N. Adult development is implicit in staff development. Journal of Staff Development, 1980, $\underline{2}$, 7-55. 
Orlich, Donald C. A comprehensive theory for in-service education. Unpublished paper, 1982. (Available from Washington State University, Pullman, WA.).

Owen, Louise. The placement and preparation of the handicapped child in the regular classroom. Kappa Delta Pi Record, 1978, 15, 58-59.

Panda, K. C. \& Bartel, N. P. Teacher perception of exceptional children. Journal of Special Education, $1972, \underline{6}, 261-266$.

Pappanikou, A. Mainstreaming. Teacher Education and Special Education, 1979, 2, 51-58.

Pau 1, J. L., Turnbull, A. P. \& Cruickshank, W. M. Mainstreaming: A practical guide. Syracuse, N.Y.: Syracuse University Press, 1977.

Payne, R., \& Murray, C. Principals' attitudes toward the integration of the handicapped. Exceptional Children, $1974,41,123-125$.

Pederson, Joe F. An assessment of vocational teachers' needs for in-service education in Region $\mathrm{Nine}$ of Kentucky, with recommendations for meeting those needs (Doctoral dissertation, University of Kentucky, 1974). Dissertation Abstracts International, 1974, 34 6535-A (University Microfilms No. 74-9320)

Piaget, Jean. Intellectual evaluation from adolescence to adulthood. Human Development, 1972, 15.

Poulos, T. H. Attitudes toward the deaf: A Guttman facet theory analysis of their content, structure, and determinants (Doctoral dissertation, Michigan State University, 1970). Dissertation Abstracts International, $1971,31,5891-\mathrm{3}$. (University Microfilms No. $71-11, \overline{9} 46)$

Rapier, J., Adelson, R., Carey, R., \& Croke, K. Changes in children's attitudes toward the physically

handicapped. Exceptional Children, 1972, 39, 219-223.

Rehage, K. V. For workshop planners. Elementary School Journal, 1959, 60, 122-123.

Reich, C., Hambleton, D., \& Houldin, B. The integration of hearing impaired children in regular classrooms. American Annals of the Deaf, $1977,122,534-543$. 
Reid, W. R., Reid, B. A., Whorton, J. E., \& Richard, C. L. An experimental special education program for college freshmen. Journal of Special Education, 1972, $\underline{6}$, $127-133$.

Rosenthal, R., \& Jacobson, L. Pygmalion in the classroom: Teacher expectation and pupil's intellectual development. New York: Holt, Rinehart \& Winston, 1968 .

Rusalem, H. Engineering changes in public attitude toward a severely disabled group. Journal of Rehabilitation, $1967,33,26-27$.

Ryan, T. J., \& Moffitt, A. R. Evaluation of preschool programs. Canadian Psychologist, 1974, 15, 205-219.

Santmire, T. E. (cited in Wilsey \& Killion, 1982). Developmental differences in adult leaders: Implications for staff development (Position paper), 1979 .

Sarbin, T. R., \& Allen, V. L. Role enactment, audience feedback and attitude change. Sociometry, 1964, 27, 183-193.

Schild, Robert J. A Study of certain practices and proposed directions for in-service programs in selected schools (Doctoral dissertation, Teachers College, Columbia University, 1964). Dissertation Abstracts International, $1964, \underline{25}, 83$.

Seltz, Anne. In-service training: Maxi-model. In Winifred Northcott (Ed.), The hearing impaired child in a regular classroom: Preschool, elementary, and secondary years. Washington, D.C.: Alexander Graham Bell Association for the Deaf, 1973.

Sharma, Toni. Inservicing the teachers. Phi Delta Kappan, $1982,63,403$.

Shears, L. M., \& Jensema, C. J. Social acceptability of anomalous persons. Exceptional Children, 1969, 36, 91-96.

Shotel, J. R., Iano, Richard, \& McGettigan, J. Teacher attitudes associated with the integration of handicapped children. Exceptional Children, 1972, 38 $677-683$.

Shroedel, J., \& Schiff, W. Attitudes toward deafness among several deaf and hearing populations. Rehabilitation Psychology, 1972, 19, 59-70. 
Silberman, M. L. Behavioral expression of teacher attitudes toward elementary school scudents. Journal of Educational Psychology, 1969, 60, 402-407.

Siller, J., Ferguson, L. T., Chipman, A., \& Vann, D. H. Attitudes of the non-disabled toward the physically disabled: Studies in reaction to disabilities. New York: New York University Press, 1967, XI.

Triandis, H. C. Attitude and attitude change. New York: John Wiley, 1971.

Tringo, J. L. The Lierarchy of preference toward disability groups. Journal of Special Education, 1970, $\underline{4}, 295-306$.

Vacc, N., \& Kirst, N. Emotionally disturbed children and regular classroom teachers. Élementary School Journal, 1977, 27, 309-317.

Wandt, E. The measurement of teacher attitudes toward groups contacted in the school. Journal of Educational Research, 1952, 46, 113-122.

Watts, W. A. Relative persistence of opinion change induced by active compared to passive participation. Journal of Personality and Social Psychology, 1967, 5, $4-15$.

Williams, R. J., \& Algozzine, B. Differential attitudes toward mainstreaming: An investigation. Alberta Journal of Educational Research, 1977, 23,

Williams, R. J., \& Algozzine, B. Teachers' attitudes toward mainstreaming. Elementary School Journal, $1979,80,63-67$.

Wilsey, Cathy, \& Killion, Jollene. Making Staff development programs work. Educational Leadership, $1982, \underline{40}, 36-38$.

Wilson, E. D., \& Alcorn, D. Disability simulation and development of attitudes toward the exceptional. Journal of Special Education, 1969, 3, 303-307.

Wood, F. H., McQuarrie, Jr., F. O., \& Thompson, S. R. Practitioners and professors agree on effective staff development practices. Educational Leadership, 1982, $\underline{40}, 28-31$.

Wood, F. H., \& Neill, J. T. A study of effects of IDEA clinical workshops: Report two. Melbourne, Fla.: Kettering Foundation, 1976. 
Wood, F. H., \& Neill, J. T. Experiential learning: An alternative approach to staff development. Texas Tech Journal of Education, 1978, 5, 113-122.

Wood, F. H., \& Thompson, S. Guidelines for better staff development. Educational Leadership, 1980, 37, $374-378$.

Wood, F. H., Thompson, S., \& Russell, Sister Frances. Designing effective staff development programs. In Betty-Dilion Peterson (Ed.), Staff development/organization development. Alexandria, Va.: ASCD, 1981 .

Yarger, S., Howey, K., \& Joyce, B. Inservice teacher education. Palo Alto: Booksend Laboratory, 1980.

Yater, Verna. St. Louis County hearing clinician program. Volta Review, 1972, 74, 247-255.

Yater, Verna. Mainstreaming of children with hearing loss: Practical guidelines and implications. Springfield, Il1.: Charles C. Thomas, 1977.

Yates, J. R. Model for preparing regular teachers for mainstreaming. Exceptional Children, 1973, 39, $471-472$.

Yuker, H. E., Block, J. R., \& Campbell, W. J. A scale to measure attitudes toward disabled persons: Human resources study number 5 . Albertson, N.Y.: Human Resources Foundation, 1960. 


\section{Selected References}

Angrilli, A., \& Liebman, B. Small voluntary discussion group, its use in teacher education. Journal of Teacher Education, 1961, 12, 421-426.

Anthony, W. A. The effects of contact on an individual's attitude toward disabled persons. Rehabilitation Council Bulletin, 1969, 12, 168-171.

Barngrover, E. A. A study of educators' preferences in special education programs. Exceptional Children, 1971,37 754-755.

Bradfield, A. R., Brown, J., Kaplan, P., \& Stannard, R. E. Special education in the regular classroom. Exceptional Children, 1973, 39, 384-390.

Brooks, B. L., \& Bransford, L. Modification of teacher's attitudes toward exceptional children. Exceptional Children, 1971, 38, 259-260.

Brophy, J., \& Good, T. Teachers' communication of differential expectations for children's classroom performance: Some behavioral data. Journal of Educational Psychology, 1970, 61, 365-374.

Brophy, J., \& Good, T. Individual differences: Toward an understanding of classroom life. New York: Holt, Rinehart \& Winston, 1973.

Cotterell, J. Matching teaching to learners. Psychology in the Schools, $1982,19,106-112$.

Foley, James. Effect of labeling and teacher behavior on children's attitudes. American Journal of Mental Deficiency, $1979,83,3 \overline{80-384}$.

Foster, G. \& Ysseldyke, J. Expectancy and halo effects as a result of artificially induced teacher bias. Contemporary Educational Psychology, 1976, 1, 31-45.

Gorman, P. Orienting children in regular schools toward impairments. Australian Journal of Mental Retardation, $1 \overline{979}, 5,13-18$.

Herr, D. E., Algozzine, B., \& Eaves, R. C. Modification of biases held by teacher trainees toward the disturbingness of child behaviors. The Journal of Educational Research, 1976, 69, 261- 264 . 
Higgs, R. W. Attitudes formation--contact or information. Exceptional Children, 1975, 41, 496-497.

Hinkle, William, \& White, Karl. Assessment and educational placement. In Milo E. Bishop (Ed.), Mainstreaming: Practical ideas for educating hearing-impaired students. Washington, D.C.: Alexander Graham Bell Association for the Deaf, 1979.

Horowitz, L. S., \& Rees, S., \& Horowitz, M. W. Attitudes toward deafness as a function of increased maturity. Journal of Social Psychology, 1965, 66, 331-336.

Kennedy, P. \& Bruinicks, R. Social status of hearing impaired children in regular classrooms. Exceptional Children, 1974, 40,336-342.

LeBue, A. C. Teachers' classroom attitudes. Journal of Teacher Education, 1959, 10, 433.

Martin, E. W. The right to education: Issues facing the speech and hearing professions. Journal of American Speech and Hearing Association, 1975, 17, 384-387.

Murphy, A. T. Attitudes of educators toward the vislidly handicapped. Sight Saving Review, 1960, 30, 157-161.

Northcott, W. H. (Ed.). The hearing impaired child in a regular classroom. Washington, D. C.: Alexander Graham Bell Association for the Deaf, 1973.

Norusis, Marija. Statistical packages for the social sciences: Introductory guide. San Francisco: MCGraw-Hill, 1982.

Ottoman, Ronald A. Mainstreaming: Initial steps in a difficult process. Educational Horizons, 1981, 59 $198-200$.

Perlman, M., \& Dubrovin, V. The exceptional child in the regular classroom. Curriculum Review, 1978, 17, 258-259.

Proctor, Doris. An investigation of the relationships between knowledge of exceptional children, kind and amount of experience, and attitudes toward their classroom interaction (Doctoral dissertation, Michigan State University, 1967). Dissertation Abstracts International, 1967, 28, 1721-A. (University Microfilms No. 67-14, 538) 
Siller, J., \& Chipman, A. Factorial structure and correlates of the attitude toward disabled persons scale. Educational and Psychological Measurements, $1964, \underline{24}, 831-839$.

Vernon, M., \& Pricket, Jr., N. Mainstreaming: Issues and a model plan. Audiology and Hearing Education, 1976, $\underline{2}, 5-11$.

Warner, S. A., \& Turner, D. R. Attitudes of professionals and students toward exceptional children. Training School Bulletin, 1966, 62, 136-144.

Warner, S. A., Turner, D. R., \& Brody, D. S. Can education students' attitudes toward the retarded be changed? Mental Retardation, 1964, 2, 235-242.

Yates, J. R. Model for preparing regulaz classroom teachers for mainstreaming. Exceptional Children, 1975, 41, 496-497.

Yuker, H. E., Block, J. R., \& Young, J. H. The measurement of attitudes toward disabled persons. Albertson, N.Y.: Human Resources Center, 1970. 
APPENDIX A

Observation Forms for Consistent

Presentation of Workshops 


Low
Business-like

April 9

Administration Building

Active Group

Alison Burr, teacher 


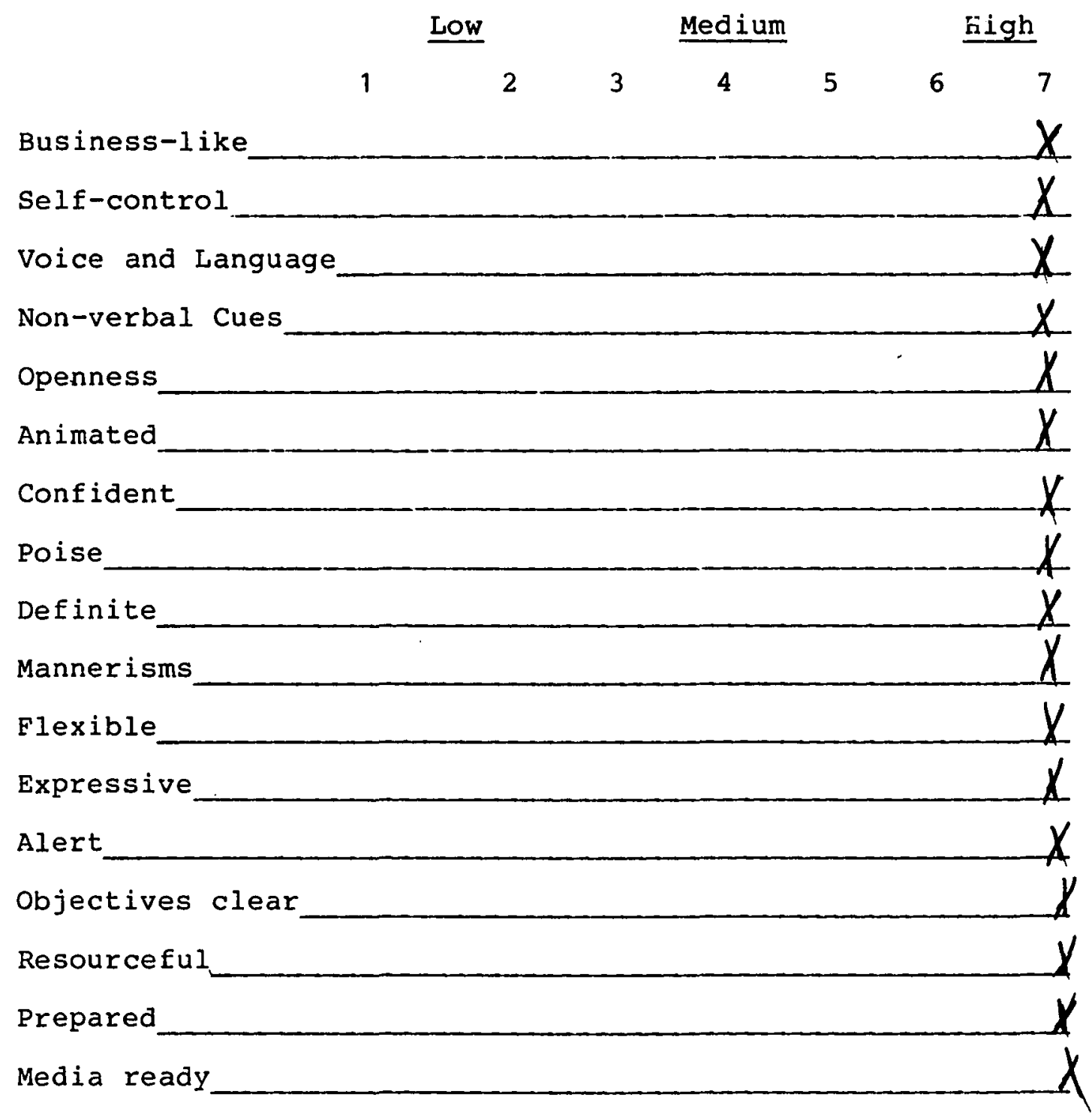

April 19

Montclair School

Passive Group

Pam Van Buskirk, teacher 


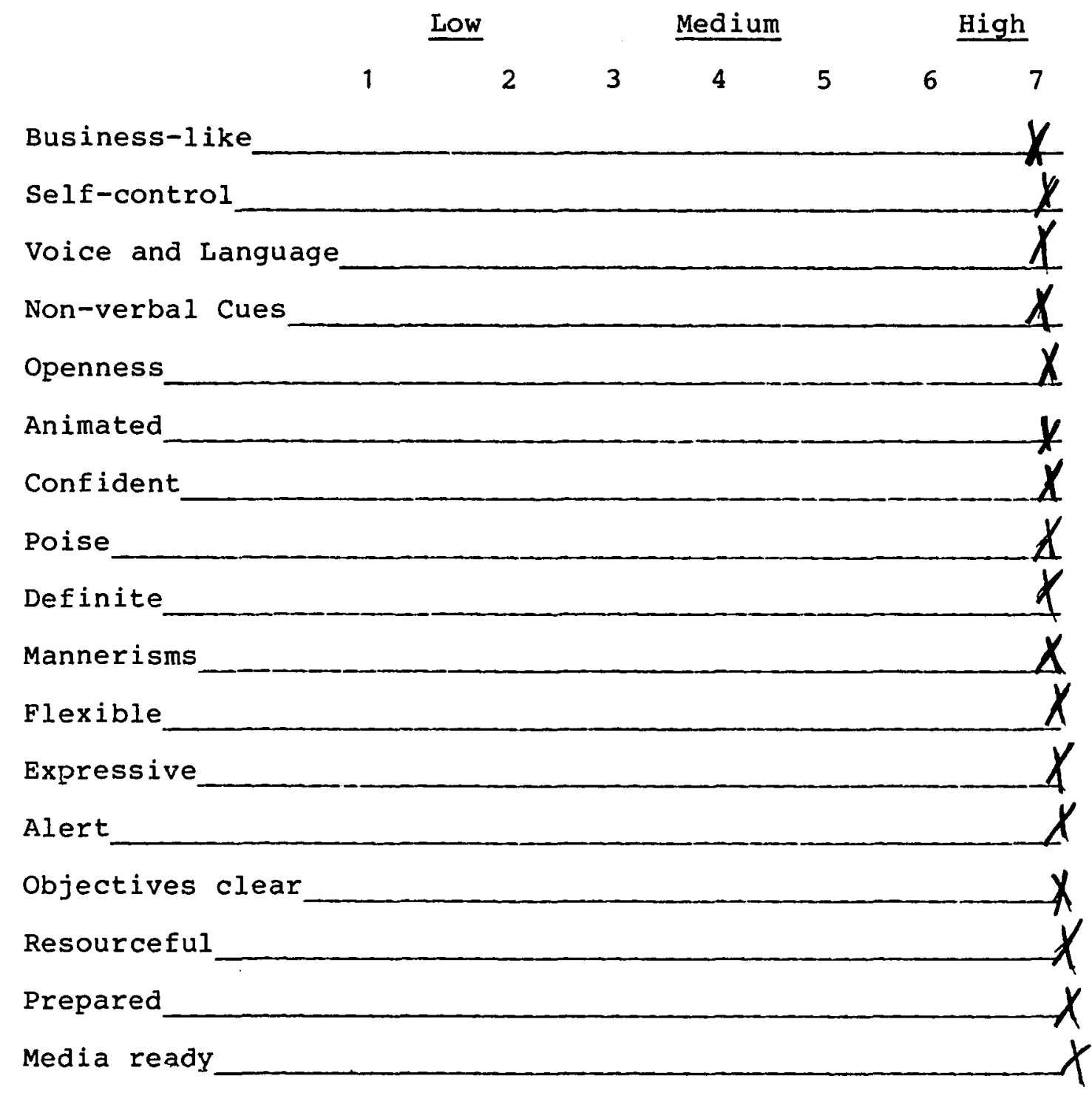

April 20

Montclair School

Active Group

Pam Van Buskirk, teacher 


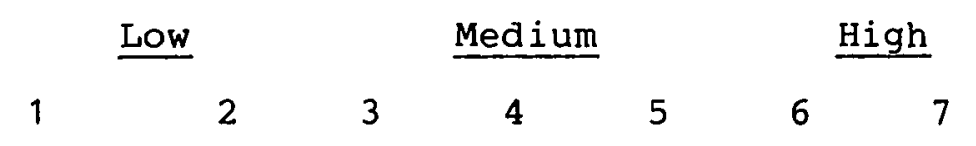

Business-like___ $X$

Self-control ___

Voice and Language ___

Non-verbal Cues________

Openness ___ $X$.

Animated ___ $\quad \times$

Confident________ $x$

Poise ___

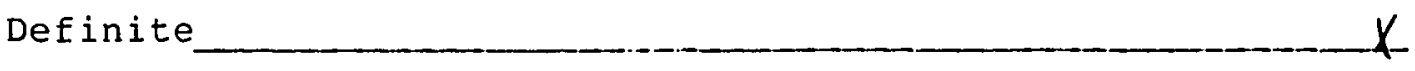

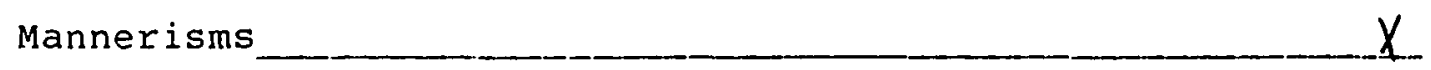

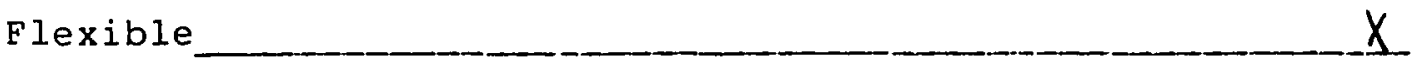

Expressive ___

Alert

Objectives clear ___

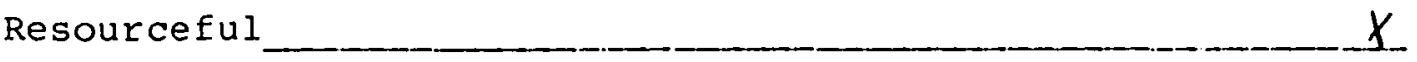

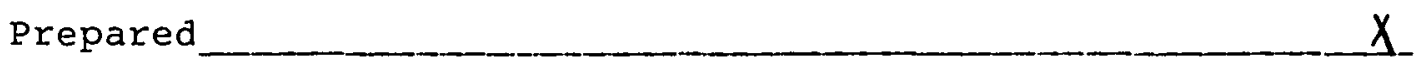

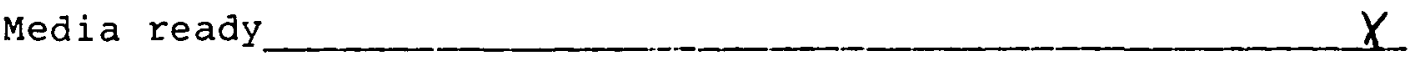

April 28

Aloha Park School

Passive Group

Bill Brelje, hearing-impaired expert 


Low
Business-like

April 29

Aloha Park School

Active Group

Bill Brelje, hearing-impaired expert 
APPENDIX B

Attitudes to Deafness Scale 
The sentences below are about deafness and deaf people. Read each sentence. Then circle the letter or letters which show how you feel about each sentence. If you strongly agree with what a sentence says, circle "SA" to the left of the sentence; if you agree, circle "A"; if you disagree, circle "D"; and if you strongly disagree, circle "SD". It is important that you "answer" each sentence. THIS IS NOT A TEST. You will not be graded. There is no best answer. Your opinion will be the right answer.

$\mathrm{SA}=$ Strongly Agree; $A=$ Agree; $D=D$ i sagree; $S D=$ Strongly Disagree

$S A A D$ SD 1 . The deaf generally have a less mature personality than the hearing. $S A A C S D 2$. In general, deaf people are more neurotic than those who hear.

$S A A C S D$ 3. It is impossible to really get "close" to a deaf person.

SA A D SD 4. Deaf people somehow seem sadder and more wrapped up in themseives than hearing people.

SA A 0 SD 5. The deaf do not seem to be bothered by ordinary life events any more than hearing people.

SA A D SD 6. Because of his need to be pitled, it is particularly important that the deaf person have someone very tolerant to whom he can talk.

SA A D SD 7. Deaf people also seem to have more than the usual number of other physical complaints.

SA A D SD 9. Deaf people show personality characteristics whlch frequently make them seem odd.

SA A D SD 9. A person who is deaf is as apt to be born a leader as anyone else.

SA A D SO 10. Deaf people seem to be overly pollte.

SA A D SD 11. Most deaf people feel that they are worthless.

SA A D SD 12. Most deaf people are dissatlsfled with themselves.

SA A D SD 13. The deaf have as many interests as the hearing have.

SA A D SD 14. The deaf adult is not quite as mature of "grown up" as the hearing adult.

SA A D SD 15. It's difflcult to understand the deaf because they keep to themselves so much.

SA A D SD 16. It must be bltterly degrading for a deaf person to depend so much on others.

$S A A C S 17$. On the whole, deaf chlldren seem to be less intelligent than hearling chlldren.

SA A D SO 15. A deaf person can't afford to talk back to people.

$S A A D S D$ 19. You should not expect too much from a deaf person.

SA A D SD 20. A deaf person is constantly worrled about what might happen to him.

$S A$ A D SD 21. A deaf person is not afrald to express his feelings.

SA A $D$ SD 22. Deaf people are more easily upset than people who can hear.

$S A A$ D SO 23. The deaf are prone to have many more fears about the world than the hearing.

SA A D SD 24. The deaf are usually on their guard with people.

SA A D SD 25. I feel that deafness is as hard to bear as complete paralysis. 
APPENDIX C

Teacher Scale of Attitudes Toward the Hearing-Impaired Student 
The sentences below are about hearing-Impaired students. Read each sentence. Circle the letter or letters which show how you feel about each statement. If you strongly agree, circle "SA" to the left of the sentence: if you agree, circle "A"; if you disagree, circle "D"; and if you strongly disagree, circle "SD". It is important that you "answer" each sentence. THIS IS NOT A TEST. You will not be graded. There is no best answer. Your opinion will be the right answer.

SA A D SD 1. Hearing-impalred chlldren tend to be shy.

$S A A D S D$ 2. Hearing-impaired children don't appreciate what their teacher does for them.

SA A $D$ SD 3. If a hearing-impaired chlld falls, it is not the fault of the teacher.

SA A D SD 4. Hearing-impaired children expect too much from the teacher.

SA A D SD 5. Hearing-impaired chlldren want their own way.

SA A D SD 6. Hearing-impalred children have a difflcult time following directions.

SA A D SO 7. Hearing-impaired children ask too many questions.

SA A D SD 8. Hearing-impaired children lack imagination.

SA A D SO 9. Standards of work should be less for a hearing-impaired chlld.

SA A D SD 10. Hearing-impalred children are discipline problems.

SA A D SO 11. Hearing-impaired children have a difficult time paying attention to the teacher.

SA A D SD 12. Hearing-Impaired children do not work hard enough.

SA A D SD 13. Hearing-impaired children are susplcious of the teacher.

$S A A D$ SO 14. Hearing-impaired students are slow in learning new mater 1 al.

$S A A$ SD 15. Hearing-impaired children tend not to trust the teacher.

SA A D SD 16. Teachers are more lenlent toward hearing-impaired children.

SA A D SD 17. Normal students learn less when hearing-impaired children are placed in the regular classroom.

$S A A$ SD 18. Hearing-impaired children are immature compared to normal children.

SA A D SD 19. Teachers should expect less from hearing-impaired students.

SA A D SD 20. Normal children will tend not to play with a hearing-impaired child.

SA A D SD 21. Normal children feel sorry for the hearing-impalred child.

$S A A D$ SD 22. The normal child cannot learn from the hearing-impaired child.

SA A D SO 23. Hearing-impalred children should not participate in the regular classroom.

SA A $D$ SD 24. Because hearing-impalred chlldren make strange noises, they disrupt the regular classroom.

SA A D SD 25. Normal children will tend to be more tolerant of hearing-impaired children if they attend class together.

Teacher Scale of Attitudes Toward the Hearing-Impaired Student Copyright $\boldsymbol{\mathcal { O }}_{1983}$ by Anita Bell McClain 


\author{
APPENDIX D \\ Original Test Items \\ for \\ Teacher Scale of Attitudes Toward the \\ Hearing-Impaired student
}


SA A D SD 1. Hearing-impaired chlldren tend to be shy.

SA A D SD 2. Hearing-impaired chlldren don't appreciate what their teacher does for them.

SA A D SD 3. Hearing-impaired children are difflcult to understand.

$S A A$ D SD 4. If a hearing-impaired child falls, it is not the fault of the teacher.

SA A D SD 5 Hearing-Impaired children expect too much from the teacher.

SA A D SD 6. Hearing-impalred children want their own way.

SA A $D$ SD 7. Hearing-impalred children have a difficult time following directions.

SA A D SD B. Hearing-lmpaired children ask too many questions.

SA A D SD 9. Hearing-impalred chlldren have a difflcult time understanding the teacher.

SA A D SD 10 Hearing-impalred children lack imagination.

SA A D SD 11. Standards of work should be less for a hearing-impalred child.

SA A D SD 12. Hearing-impaired children are discipline problems.

SA A D SD 13. Hearing-impaired children have a difficult time paying attention to the teacher.

SA A D SD 14. Hearing-impalred chlldren do not work hard enough.

SA A D SD 15. Puplls who are hearing-impaired make the teacher's task more unpleasant.

SA A D SD 16. Hearing-Impaired chlldren are susplclous of the teacher.

SA A $D$ SO 17. Hearing-impalred students are slow in learning new material.

SA A D SD 15. Pupils who are hearing-impalred can be very boring.

SA A D SD 19. Hearing-Impalred children tend not to trust the teacher.

SA A D SD 20. Hearing-impaired chlldren must be told step-by-step what to do.

SA A D SO 21. Teachers are more lenlent toward hearing-impaired children.

SA A D SD 22. Hearing-impaired students try one's patience.

SA A D SD 23. Normal students learn less when hearing-impaired chlldren are placed in the regular classroom.

SA A D SO 24. Hearing-impalred children are immature compared to normal children.

SA A D SD 25. Teachers should expect less from hearing-impalred students.

SA A D SO 26. Normal children will tend not to play with a hearing-impaired child.

SA A D SD 27. Hearling-impaired chlldren tend to be physical toward their peers.

SA A D SD 28. Normal children feel sorry for the hearing-impaired child.

SA A D SD 29. The normal chlld cannot learn from the hearing-impaired child.

SA A D SD 30. Hearing-impaired chlldren should not participate in the regular classroom.

SA A D SD 31. Hearing-impalred children tend to be physical toward the teacher.

SA A D SD 32. Because hearing-impaired children make strange noises, they disrupt the regular classroom.

SA A D SD 33. Normal children will tend to be more tolerant of hearing-impalred children if they attend class together.

SA A D SD 34. Hearing-impaired children tend to be refected by peers. 
APPENDIX E

Letter to Principals from Deputy Superintendent 
February 17,1982

TO: Elementary Principals

FROM: George Russell

I have given Anita McClain permission to gather data from teachers for her doctoral study. Whether teachers choose to participate is strictly up to each of them individually.

We have chosen randomly about 150 elementary teachers distributed evenly between the primary and upper grades. Each of those teachers will get a letter from Anita explaining her program and asking them to participate in a study she is conducting for her doctorate. From the 150, she hopes that at least 90 will choose to become involved in her project. Essentially, the program is as follows: 30 of the selected teachers will take a short 20-minute test having to do with attitudes toward mainstreaming hearing impaired children. Thirty more will be given a two-hour inservice program after which they will be surveyed concerning their attitudes on the topic. Another 30 will be given a different two-hour inservice session which will be followed up by the survey.

If the 60 teachers choose to participate in the inservice portion, they will be asked to take part in a two-hour workshop on April 9--half of them in the morning, the other half in the afternoon. That is a teacher workday without students. Again, whether a teacher decides to participate is strictly up to that teacher. The puprose of this memo is to bring to your attention the fact that some of your teachers may receive such a letter. I encourage you to encourage them to take part. The findings of the study could be of some value to us. 
APPENDIX F

Workshop Participation Letter 


\section{Lewis \& Clark College}

February 16, 1982

Dear

I would like to invite you to participate in a two-hour workshop on better understanding the hearingimpaired child who will be mainstreamed into the regular classroom. The workshop will be held at the Beaverton School Administration Building, conference rooms 1 and 2 , on April 9th, a teachers' workday at

If you participate, you will gain a better understanding of the hearing-impaired child and to more effectively integrate that child into the regular classroom. You will also be entitled to two hours of consultation time from Dr. Bill Brelje, Director, Special Education: Hearing Impaired, at Lewis and Clark College, and myself. The study will assist me in research for the hearing-impaired and I will see to it that you receive these results.

Respectfully,

Anita McClain

Department of Education

$\mathrm{AM} / \mathrm{sd}$ 
APPENDIX G

Control Group Letter 
Lewis \& Clark College

February 16,1982

Dear

I would Iike to invite you to participate in a study concerning th mainstreaming of hearing-impaired children into the regular classroom. Specifically, you would be given a teacher attitude scale asking yu to ate specific attributes of hearing disabled children as they relate to the teacher, peers and the classroom.

I plan to visit yur building on give you the scale. It will take no longer than fifteen minutes. If this is not convenient, pease call me at 246-0781 or 244-6161, Extension 283.

If you elect to participate, you should gain insight as to the effectiveness of teacher attitudes as they relate to mainstreaming the hearing-impaired child. The results will help me to collect data for a study on this topic and I will see to it that you receive these results. The results should be of benefit to you if you receive hearing-impaired children into your classroom in the future. As a participant, you are also entitled to two hours of consultation time regarding successful integration of the hearing-impaired child into the regular classroom from $D r$. Bill Brelje, Director, Special Education: Hearing Impaired, at Lew is and clark, and myself.

Respectfully,

Anita McClain

Department of Education

$\mathrm{AM} / \mathrm{sd}$ 
APPENDIX H

Participant Response Letters 
Please return this response by February 25, 1982, via inter-school mail. Return enveloped enclosed.

I would like to participate and will be available to rate the attitude scale.

I I cannot participate.

REASON :

Name

School 
Please return this response by February 25, 1982, via inter-school mail. Return envelope enclosed.

I would like to participate in the Workshop,

"Understanding the Hearing-Impaired Child."

I do not wish to participate in the workshop.

Reason:

Name

School 
APPENDIX I

Second Workshop Participant Letters 


\section{Lewis \& Clark College}

March 3, 1982

Dear

You, along with several other teachers, indicated that you could not spare any time from your teacher planning day to attend a workshop, "Understanding the Hearing-Impaired Child."

I would like to ask you to reconsider attending at a more appropriate time. Please note, I have also shortened the workshop to one hour. The workshops will be offered at the following times and places:

3:15-4:15 p.m. on April 19th at Montclair School

3:15-4:15 p.m. on April 28th at Aloha Park School

Your valuable time and input would be appreciated.

Respectfully,

Anita McClain

Department of Education

$\mathrm{AM} / \mathrm{sd}$ 
Lewis \& Clark College

March 3, 1982

Dear

You, along with several other teachers, indicated that you could not spare any time from your teacher planning day to attend a workshop, "Understanding the Hearing-Impaired Child."

I would like to ask you to reconsider attending at a more appropriate time. Please note, I have also shortened the workshop to one hour. The workshops will be offered at the following times and places:

3:15-4:15 p.m. on April 20th at Montclair School

3:15-4:15 p.m. on April 29th at Aloha Park School

Your valuable time and input would be appreciated.

Respectfully,

Anita McClain

Department of Education

$\mathrm{AM} / \mathrm{sd}$ 


\section{APPENDIX J}

Second Participant Response Letters 
Plese return by March 12 th via inter-school mail.

I wish to participate from $3: 15-4: 15$ on April

19 th at Montclair School.

- I wish to participate from 3:15-4:15 on April 28th Aloha Park School.

I do not wish to participate.

Reason

Name

School 
Plese return by March 12 th via inter-school mail. I wish to participate from 3:15-4:15 on April 20 th at Montclair School. I wish to participate from 3:15-4:15 on April 29th Aloha Park School. I do not wish to participate.

Reason

Name

School 
APPENDIX $\mathrm{K}$

Letter to Principals 


\section{Lewis \& Clark College}

March 3, 1982

Dear

As George Russell indicated in a recent letter to you, some of your teachers will be receiving letters (such as that enclosed) regarding a research study.

Any help you could give me in encouraging your teachers to attend the workshop would be appreciated.

The study I am designing has implications concerning teacher attitudes toward the hearing-impaired child in the regular classroom. Further implications involve the value of district in-service workshops; specifically, that type of workshop which might affect the most impact regarding desired outcomes.

Your time and attention to this would be helpful.

Respectfully,

Anita McClain

Department of Education

Enclosure 
APPENDIX L

Third Workshop Participant Letter (Active Group) and Participant Response Letter 
March 3, 1982

Dear

I would like to invite you to participate in a one-hour workshop on better understanding the hearingimpaired child who will be mainstreamed into the regular classroom. The workshop will be held from 3:15-4:15 p.m. on Tuesday, April 20 at Montclair School, or from 3:15-4:15 p.m. on Thursday, April 29 at Aloha Park School.

If you participate, you will gain a better understanding of the hearing-impaired child and to more effectively integrate that child into the regular classroom. You will also be entitled to two hours of consultation time from Dr. Bill Brelje, Director, Special Education: Hearing-Impaired, at Lewis and Clark College, and myself. The study will assist me in research for the hearing-impaired and $I$ will see to it that you receive these results.

Respecfully,

Anita McClain

Department of Education

$\mathrm{AM} / \mathrm{sd}$ 
Please return by April 1 st via inter-school mail in the envelope provided.

I wish to participate from $3: 15-4: 15$ on April 20 th at Montclair School.

I wish to participate from 3:15-4:15 on April 29th Aloha Park School.

I do not wish to participate.

Reason

Name

School 
APPENDIX M

Third Workshop Participant Letter (Passive Group) and Participant Response Letter 


\section{Lewis \& Clark College}

March 3, 1982

Dear

I would like to invite you to participate in a one-hour workshop on better understanding the hearingimpaired child who will be mainstreamed into the regular classroom. The workshop will be held from 3:15-4:15 p.m. on Monday, April 19 at Montclair School, or from 3:15-4:15 p.m. on Wednesday, April 28 at Aloha Park School.

If you participate, you will gain a better understanding of the hearing-impaired child and to more effectively integrate that child into the regular classroom. You will also be entitled to two hours of consultation time from Dr. Bill Brelje, Director, Special Education: Hearing-Impaired, at Lewis and Clark College, and myself. The study wil assist me in research for the hearing-impaired and $I$ will see to it that you receive these results.

Respecfully,

Anita McClain

Department of Education

$A M / s d$ 
Please return by April 1st via inter-school mail in the envelope provided.

I wish to participate from $3: 15-4: 15$ on April

19 th at Montclair School.

I wish to participate from 3:15-4:15 on April 28th

Aloha Park School.

I do not wish to participate.

Reason

Name

School 
APPENDIX N

Workshop Visuals 
Workshop Visuals

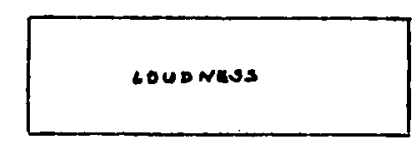

Middle-ear loss

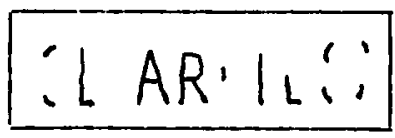

Interprets as CLEARNESS

inner-ear loss

Hearing Aids

High gain aid -- severe loss (70-90 db loss) and profound loss ( $90+d b$ loss)

Low gain aid -- mild loss (20-50 db loss) and moderate loss (50-70 db loss) All might include a loss in the normal pitch range of 250-4000 cycles per second

Feedback -- high pitched ring caused by close proximity of the amplifier and the receiver or poor fitting ear mold

Microphone -- picks up sound waves and changes them to electrical signals

Amplifier -- increases intensity of signal

Receiver -- changes electrical signals back into sound

Volume waves

control -- adjusts volume

Battery

location -- usually transistors 
Non-Verbal Communication

Interpret statements by using one or a combination of the following:

1. 1 ip read

2. finger spell--manual alphabet or traditional orthography

3. dramatization--whole body, or facial expressions

4. sign language

Statements:

I feel sick.

May I stay in at recess?

May I go to the bathroom?

My mom is picking me up early.

I do not understand how to do the math.

What page am I supposed to do?

I forgot my homework.

I have lost my pencil.

I forgot my lunch. 
APPENDIX $O$

Reminder Letter 


\section{Lewis \& Clark College}

Dear

Thank you very much for your interest and time to attend the workshop, "Better Understanding the HearingImpaired Child."

I'd like to remind you of the date and time at

I look forward to seeing you then.

Respectfully,

Anita McClain

$\mathrm{AM} / \mathrm{sd}$ 